\title{
De la periferia al centro. (Cuba, Puerto Rico y Filipinas en la crisis del Imperio español)
}

\author{
Josep M. Fradera \\ Universitat Pompeu Fabra (Barcelona)
}

\begin{abstract}
El Imperio español quebró por completo a principios de la tercera década del siglo XIX. De su ruina, España conservó tres importantes posesiones, dos en el Caribe (Cuba y Puerto Rico) y una en el Mar de China, Filipinas. El artículo estudia la transformación del nexo colonial que hizo posible que aquellos enclaves insulares se mantuviesen bajo control español. Se estudian las políticas que alli se desarrollaron en respuesta al impacto militar que significaron las tomas de La Habana y Manila durante la guerra de los Siete Años y de qué manera éstas deben comprenderse como parte de un proceso general de transformación que superaba ampliamente el marco colonial en el que aquellas posesiones se encontraban insertas.
\end{abstract}

PALABRAS CLAVE: Imperio y colonialismo, monopolios fiscales y plantación, reformas administrativas y militares.

The break up of the Spanish Empire was completed at the beginning of the third decade of the XIXth century. Out of its ruins, Spain managed to keep three important possessions, two in the Caribbean (Cuba and Puerto Rico) one in the China sea (Philippines). This paper examines the transformation of the colonial nexus that made possible for Spain to keep those insular enclaves under control. The policies developed as a response to the military impact due to the takeover of Habana and Manila during the Seven Year's War are evaluated. They are analysed in the context of a general transformation process that went beyond the colonial framework of those specific possessions.

Keywords: Empire and Colonialism; Monopolies and Plantations; Military and Administrative Reforms.

Entre la década de 1760 y 1820, aproximadamente, periferias insulares del mundo colonial español como Cuba, Puerto Rico y Filipinas fueron incorporándose a la economía y a la política del imperio con mucha mayor intensidad que hasta entonces. De ser partes muy dependientes de un sistema más amplio, su transformación interna las convirtió en posesiones importantes de la Corona, interesantes por sí mismas desde el punto de vista colonial, en un proceso que comportó una modificación muy sustantiva de su relación tanto con el conjunto imperial como con la metrópoli. Al final de este proceso, la crisis del sistema imperial que culminó en la secesión de la América continental convirtió a aquellos enclaves en las únicas colonias dignas de tal nombre de una potencia mundial 
en ruinas. Sin embargo, diversos factores permitieron a España prolongar casi cien años su presencia en el Caribe y en el Mar de China hasta fines del siglo XIX. En este trabajo trataremos de acercarnos a los factores políticos y económicos que permitieron a España estabilizar el dominio colonial sobre los tres enclaves insulares. Conviene recordar, para empezar, algunos de los aspectos más sustanciales de aquella transformación, que permitió a España prolongar una presencia colonial ya centenaria en un momento crucial de pugna por el dominio del mundo extra-europeo, que se prolonga desde la guerra de los Siete Años (1757-1763) y culmina en las guerras napoleónicas. Este fue un periodo de máxima tensión entre Gran Bretaña y Francia por el dominio del Atlántico y el Océano Índico, con repercusiones que alcanzaron de lleno a las todavía mayores potencias coloniales del mundo, España, Portugal y Holanda, con consecuencias que no han sido aún exploradas en todo su alcance. No se trató tan sólo de lo que en su epidermis podría denominarse la pugna por el control de las grandes rutas de navegación y del comercio marítimo, sino de una transformación completa de la naturaleza de los equilibrios entre los tipos de intercambios, las economías implicadas y los sistemas coloniales, que eran un factor esencial de su continuidad y profundización. ${ }^{1}$ Esta modificación de las relaciones de fuerza entre los países comprometidos en el dominio sobre otras partes del mundo, que no ha sido nunca explicada como un todo, así como en el interior de las propias economías y sociedades concernidas, es el escenario donde deben emplazarse razonablemente los cambios internos y externos en el espacio imperial y colonial español. El caso de las periferias insulares es muy revelador de las líneas generales del proceso de transformación al que nos estamos refiriendo.

Conviene sin duda atender a estos desarrollos con mayor precisión. Si contemplamos el enorme mundo imperial español, podremos observar de modo muy sucinto que tanto las posesiones del Caribe como Filipinas fueron mucho más importantes como plazas fuertes militares, como baluartes defensivos del imperio, que como sociedades donde proyectar formas de explotación colonial consistentes hasta muy tarde. Sobre esta base, los fac-

1 La mejor descripción de conjunto aunque ceñida exclusivamente al desarrollo del segundo imperio británico, en Bayly, C. A.: Imperial Meridian. The British Empire and the World, 1780-1830, Longman, Londres, 1989; del mismo autor: "The Second British Empire", en Winks, Robin (ed.): Historiography, The Oxford History of the British Empire, Oxford University Press, Oxford, 1999, págs. 54-72. 
tores de cambio que aparecen en el siglo XVIII pueden ser individualizados con cierto detalle. En el espacio caribeño, la cara más dinámica del universo imperial hispánico tardío, la economía de plantación con esclavos en torno a algunos pocos pero muy decisivos productos de la agricultura tropical, permitió que Cuba y Puerto Rico pasasen en pocos años de ser básicamente enclaves militares con una agricultura extensiva y ganadera de complemento a ocupar un lugar destacado entre los productores mundiales de azúcar, café, tabaco y algunos otros productos tropicales de exportación. ${ }^{2}$ Aquel proceso fue una parte importante de la reconversión de la vieja ballena del imperio español, que dejó de ser de modo bastante exclusivo un productor de metales preciosos para el resto del mundo y reflejó una realidad más compleja, en la que la exportación de productos de la agricultura tropical permitió importar las espectaculares oportunidades que había brindado a los late comers del norte de Europa que no disponían de poblaciones autóctonas importantes o de yacimientos metalíferos de consideración. ${ }^{3}$

Filipinas era un caso aparte, por muchas y distintas razones. Baluarte defensivo de gran importancia de la retaguardia imperial, el mantenimiento de una tan lejana posesión se justificaba sobradamente por el ahorro defensivo en toda la fachada americana del Pacífico. Además, su posición intermediaria entre las economías asiáticas de la seda, el algodón y las especias con el imperio chino en particular permitió que el comercio transpacífico financiase una parte importante de su coste de mantenimiento durante siglos, al mismo tiempo que garantizaba suculentas ganancias a toda una cadena de comerciantes privilegiados en las ciudades cabecera de México y España. A partir de la segunda mitad del siglo XVIII, las diversas economías presentes en el archipiélago empezaron a experimentar cambios significativos en su articulación mercantil. ${ }^{4}$ Este cambio se manifestó tanto en las relaciones multilaterales con el entorno asiático (en muchas ocasiones a través de la actividad de los comerciantes y las mari-

2 Holtfrerich, Carl-Ludwig: "Introduction: The Evolution of World Trade, 1720 to the Present", en Holtfrerich, Carl-Ludwig (ed.): Interactions in The World Economy. Perspectives from Internacional Economic History, Harvester Wheatsheaf, New York, 1989, págs. 1-20.

3 Para el imperio español como productor de metales preciosos, en su última etapa, ver Bakewell, Peter J.: Silver Mining and Society in Colonial Mexico: Zacatecas, 1546-1700, Cambridge University Press, Cambridge, 1971; Sánchez Gómez, Julio, Mira Delli-Zotti, Guillermo y Dobado, Rafael: La savia del Imperio. Tres estudios de economía colonial, Ediciones Universidad de Salamanca, Salamanca, 1997. Sobre la economía de plantación, la síntesis de Curtin, Philip D.: The Rise and Fall of the Plantation Complex: Essays in Atlantic History, Cambridge University Press, Cambridge, 1990.

4 Reid, Anthony (ed.): The Last Stand of Eurasian Economies. Responses to Modernity in the Diverse States of Southeast Asia, St. Martin's Press, New York, 1997. 
nas supuestamente adversarias de un mundo imperial español hasta entonces hermético), en los intercambios a larga distancia, como en las formas en las que la producción se organizaba. ${ }^{5}$ En el marco de una transformación parcialmente conocida, la movilización del trabajo del campesinado local era un factor crucial en ausencia de la gran solución del mundo atlántico que había sido la plantación esclavista. La coerción ocupaba también un lugar preciso en todo ello, pero no presentó los aspectos dramáticos de la emigración forzada y de las prácticas aberrantes asociadas a la esclavitud en el mundo americano de la plantación. ${ }^{6}$ En aquel contexto de cambio social y económico, los estados europeos (el imperio español entre ellos) o los poderes autóctonos del sudeste asiático continental se aprestaron también a introducir nuevas recetas fiscales, a vincularse a las nuevas fuerzas económicas en presencia, garantizando que su capacidad de movilización del trabajo campesino a través de corvées y prestaciones económicas muy diversas estuviesen al servicio de los agentes económicos locales y la administración colonial sobre el terreno, aquella inexorable winning combination. ${ }^{7}$ Si no entendemos la estrecha conexión de la esclavitud y otras formas de trabajo inducido coercitivamente que se dieron de forma simultánea y cada vez con mayor intensidad a partir de la segunda mitad del siglo XVIII y durante los cien años siguientes, no comprende-

5 Para el comercio interasiático y con Europa debe consultarse en primer lugar el clásico de Reid, Anthony: Southeast Asia in the Age of Commerce, 1450-1680, 2 vols., Yale University Press, New Haven, 1988 y 1993; del mismo autor: Southeast Asia in the Early Modern Era, Cornell University Press, Ithaca, 1993. Una posición distinta a tener en cuenta es la de Victor Lieberman, de quien se citan otros trabajos en esta misma introducción: "Local Integration and Eurasian Analogies: Structuring Southeast Asian History, c. 1350-1830", Modern Asian Studies, 27, 1993, págs. 475-572; y "Wallerstein's System and the Internacional Context of Early Modern Southeast Asian History", Journal of Asian History, 24, 1990, págs. 70-90; de Reinhold Haellquist, Karl (ed.): Asian Trade Routes, Curzon Press, Londres, 1991; Broeze, Frank (ed.): Brides of the Sea. Port Cities of Asia from the 16th-20th Centuries, New South Wales University Press, Sydney, 1999. Finalmente, de Chaudhuri, K. N.: Asia Before Europe, Cambridge, Cambridge University Press, 1990.

6 Una muy interesante visión para todo el sudeste asiático en Reid, Anthony (ed.): Slavery, Bondage, and Dependency in Southeast Asia, St. Martin's Press, New York, 1984. También Watson, J. L. (ed.): Asian and African Systems of Slavery, California University Press, Berkeley, 1980; de Klein, Martin (ed.): Breaking the Chains. Slavery, Bondage and Emancipation $n$ Modern Africa and Asia, The University of Wisconsin Press, Madison, 1993.

7 Una visión de conjunto para toda la región en Kathirithamby-Wells, J.: "The Age of Transition: the Mid-eighteenth to the Early Nineteenth Century", en Tarling, Nicholas (ed.): The Cambridge History of Southeast Asia, vol I: From Early Times to c. 1800, Cambridge University Press, Cambridge, 1992. Jenny, David: "The Demise of Corvée and Slavery in Thailand, 1782-1913", en Klein (ed.): Breaking the Chains..., págs. 83-109. Whitmore, John K.: "Literati Culture in Dai Viet, 1430-1840", en Lieberman, Victor (ed.): Beyond Binary Histories. Re-Imagining Eurasia to c. 1830, The University of Michigan Press, Ann Arbor, 1999, págs. 236-237. 
remos jamás el sentido de la transformación a gran escala del trabajo esclavo entre 1830 y 1880, en América y, luego, en África las décadas posteriores. ${ }^{8}$ No podremos siquiera plantearnos las razones de una aparente paradoja: que los productores azucareros esclavistas del Caribe se lamentasen amargamente de la baratura del trabajo en Asia en comparación al de sus dotaciones de esclavos. ${ }^{9}$ En aquel contexto de transformación, la función de los poderes coloniales, del Estado en la colonia, del Leviatán ultramarino, fue crucial. ${ }^{10}$ Esto explica, a su vez, por qué el éxito imparable del liberalismo y de la ideología del trabajo libre en Europa no sólo no replegó a los poderes coloniales europeos en otros continentes sino que la generalizó y consolidó hasta mediados del siglo XX.

El desencadenante de los grandes cambios en la periferia insular del Imperio a los que me he referido fueron las consecuencias de la Guerra de los Siete Años, el punto de salida de la reorganización política, militar y económica de los sistemas coloniales de todos los países europeos y que, en el caso del británico, condujo en línea recta a la crisis norteamericana de un lado y a la colonización de Bengala del otro. ${ }^{11}$ En el caso imperial español, es innegable que la voluntad de reformas venía de antes y que, tanto en Cuba como en Filipinas, se habían impuesto algunas modificaciones en su organización tradicional, al tiempo que se habían formulado proyectos de renovación económica. No obstante, fue la invasión británica de Manila y La Habana, dos plazas fuertes y puertos de importancia estratégica vital para los intereses imperiales en su conjunto, el acontecimiento que precipitó cambios de mucha mayor relevancia que todo lo sucedido en los años

8 Para la abolición africana deben consultarse los trabajos fundamentales de Paul E. Lovejoy, en particular: Transformations in Slavery: a History of Slavery in Africa, Cambridge University Press, Cambridge, 1983; y Lovejoy, Paul E. y Hogendorn, Jan S.: Slow death for slavery. The course of abolition in Northern Nigeria, 1897-1936, Cambridge University Press, Cambridge, 1993. También la excelente recopilación de Miers, Suzanne y Roberts, Richard (eds.): The End of Slavery in Africa, The University of Wisconsin Press, Madison, 1988.

9 Desde el lado asiático, esta capacidad para competir aportada por el cultuurstelsel (sistema de cultivo) holandés de 1830, fue resaltada por Bulbeck, David y otros: Southeast Asian Exports since the 14th Century. Cloves, Pepper, Coffee, and Sugar, KTLV Press, Leiden, 1998, pág. 110.

10 Indicaciones muy lúcidas para un planteamiento de la cuestión en Engerman, Stanley L.: "Slavery and Emancipation in Comparative Perspective: A Look at Some Recent Debates", The Journal of Economic History, XLVI, 2, 1986, págs. 317-339.

11 Riley, James C.: The Seven Years War and the Old Regime in France. The Financial Toll, Princeton University Press, Princeton, 1986; Anderson, Fred: The Crucible of War: The Seven years War and the fate of empire in British North America, 1754-1766, Alfred A. Knopf, New York, 2000. Sobre el asalto británico definitivo a la India post-mogol, de Marshall, P. J.: Bengal the British Bridgehead, Cambridge University Press, Cambridge, 1988. 
precedentes. ${ }^{12}$ En los momentos inmediatamente posteriores a la retirada británica y a la recuperación de ambas plazas fuertes, la Corona emprendió una importante reorganización de aquellos enclaves tanto en los aspectos militares como en los fiscales y políticos. Es cierto que es muy difícil distinguir entre los tres planos, aunque es importante distinguirlos en términos analíticos. La prioridad de la monarquía era principalmente militar: el paso de una concepción de defensa selectiva del Imperio a la defensa total, una pretensión que se demostraría inalcanzable a medio plazo. ${ }^{13}$ La utopía militar de los equipos gobernantes de Carlos III forzaría a la Corona a emprender un vasto esfuerzo de defensa del Imperio y comprometería la rentabilidad económica del sistema, tanto a la hacienda pública como a los agentes privados americanos y peninsulares..$^{14}$ Las exigencias del programa de defensa y reorganización militar, sin embargo, fueron tan cuantiosas que comprometieron gravemente los tradicionales objetivos de estabilidad y pacto con los súbditos americanos del monarca. ${ }^{15}$ Es conveniente verlo con mayor detalle en el caso de las periferias insulares de las que nos estamos ocupando.

\section{Los efectos no previstos de los objetivos imperiales}

En el caso de los enclaves insulares que nos ocupan, se desplegó un ambicioso plan de fortificaciones y de reorganización de la fuerza militar disponible en cada una de ellas. En este último caso, esto comportó no solamente la reorganización de la tropa convencional sino la formación de milicias de complemento, acorde con la idea de los equipos reformistas que pri-

12 La mejor descripción del cambio en la formulación de la política imperial española en Delgado, Josep M.: Cambio institucional bajo restricciones externas. Racionalidad económica y condicionantes internacionales en el origen de las instituciones económicas del reformismo ilustrado. Una aplicación al sistema colonial español, manuscrito inédito cuya consulta agradezco al autor.

13 Archer, Christon: El ejército en el México borbónico, 1760-1810, Fondo de Cultura Económica, México, 1983; Marchena Fernández, Juan: Ejército y milicias en el mundo colonial americano, Mapfre, Madrid, 1992.

14 Barbier, Jacques y Klein, Herbert S.: "Las prioridades de un rey ilustrado: el gasto público bajo el reinado de Carlos III", Revista de Historia Económica, 3:3, 1986, págs. 473-496. Barbier, Jacques: "Indies Revenues and Naval Spending: The Cost of Colonialism for the Spanish Bourbon Reforms", Jahrbuch für Geschichte von Staat, Wirschaft, und Gesellschat Lateinamerikas, 21, 1984, págs. 171-188.

15 Las cifras globales del gasto militar para toda la Monarquía en Delgado, Josep M. y Fontana, Josep: "La política colonial española", en Tandeter, Enrique (dir.): Historia General de América, vol. IV, Ediciones Unesco/Editorial Trotta, Madrid, 2000, pág. 24. 
maba la defensa total en lugar de la obsoleta concepción del siglo XVII de un sistema de plazas fuertes. Como afirmaba a su llegada a Cuba el conde de Ricla: "La fuerza verdadera para frustrar la conquista de un país no consiste en las murallas, ni en el valor de las guarniciones, sino en la que tenga y encierre en sí mismo el país para concurrir en todo a la defensa tanto atendiendo a la calidad del terreno para defensa de pasos precisos, producción de víveres, acopio y medios de conducirlos, como al número de habitantes divididos en clases, para que cada uno sea útil al servicio de la patria en caso de guerra, ya sea con las armas como milicianos o en su trabajo personal, como paisanos deben defender a su rey, haciendas, casas y familia" ${ }^{16}$ Pocas dudas caben de que habían tomado buena nota no sólo del riesgo externo en un escenario clave de las guerras del siglo XVIII como era el Caribe, sino también de la precariedad de la lealtad de los criollos con quienes deberán pactar el alcance de cualquier reforma. Allan Kuethe estudió con gran detalle la puesta en práctica de las ideas de Ricla y O'Reilly en la Cuba de los años posteriores a la captura de La Habana. ${ }^{17} \mathrm{El}$ aspecto más novedoso fue la organización de las milicias de complemento, en la medida en que permitían matar tres pájaros de un solo tiro: reforzar la capacidad operativa del Ejército colonial; integrar gracias al fuero militar a la potente clase de hacendados criollos en las estructuras del poder colonial; y, finalmente, incluir a los "pardos y morenos" libres (en la terminología imperial fenotípica) en las tareas de defensa imperial. ${ }^{18}$ En cuanto al ambicioso programa de fortificaciones emprendido, estaba prácticamente concluido a fines de los años ochenta. ${ }^{19}$ En correspondencia, el volumen de los situados disminuyó de manera sensible a partir de 1785 respecto a los momentos de mayor empuje fortificador de los primeros años de aquella década, con consecuencias importantes para la economía de la Isla, como veremos más adelante. ${ }^{20}$

16 Discurso de Ricla ante la Junta de América. Tomo la cita de García, Mercedes: “Tiempo de Borbones e Ilustrados: las reformas en la Cuba del Setecientos", en Illes i Imperis, 8 (en prensa).

17 Kuethe, Allan J.: Cuba, 1753-1815. Crown, Military and Society, The University of Tennessee Press, Knoxville, 1986.

18 Esta última medida no dejó de levantar las suspicacias y la renuencia de los criollos que daban su apoyo incondicional a la integración de la sociedad cubana en el ejército imperial.

19 Pérez Guzmán, Francisco: La Habana. Clave de un Imperio, Instituto Cubano del Libro, La Habana, 1997, pág. 39; Blanes Martín, Tamara: "Fortificaciones habaneras. La defensa de La Habana, del siglo XVI a la primera mitad del siglo XIX", en Guimerá, Agustín y Monge, Fernando (eds.): $L a$ Habana, puerto colonial. Siglos XVIII-XIX, Fundación Portuaria, Madrid, 2000, págs. 154-165.

20 Marichal, Carlos: La bancarrota del virreinato. Nueva España y las finanzas del imperio español, Fondo de Cultura Económica, México, 1999, pág. 50. 
Aunque no conocemos con el mismo detalle cómo fue aplicado este programa en Puerto Rico y Filipinas, no se nos escapa que su aplicación se originó en líneas generales en la misma filosofía militar. En la colonia antillana menor no respondió solamente al mismo esquema sino que fue aplicado por las mismas personas. Es el propio O'Reilly quien se desplaza a la Isla el mismo año 1765, procedente de Cuba. Allí, con el capaz ingeniero militar Tomás O'Daly, diseña un proyecto de reforma de las fortificaciones, y establece una cifra de 100.000 pesos anuales como imprescindible para llevarlo a buen puerto. ${ }^{21}$ Como es bien sabido, la modestia de los recursos propios de las tres posesiones insulares hacía del todo imposible hacer depender aquel esfuerzo de reorganización de sus propias finanzas públicas. $\mathrm{O}$, dicho de forma más precisa, era imposible desarrollar aquel programa de reforma militar sin una acrecentada implicación financiera del virreinato de Nueva España, de la que había dependido históricamente y de la que dependería de nuevo, para aquel esfuerzo extraordinario, hasta la primera década del siglo XIX. Las transferencias de recursos a través del sistema de situados hacia La Habana (y desde ella a Puerto Rico y otros lugares del espacio circumcaribeño) y Manila (que actuaba a menor escala como centro redistribuidor en el Pacífico y el archipiélago del mar de China, hacia las Marianas, así como las Islas Batanes y Mindanao en el propio archipiélago) alcanzó proporciones nunca vistas en el periodo a que nos estamos refiriendo, en un esfuerzo que agotó las cajas del Virreinato y las condujo a una bancarrota anunciada.

Las transferencias de recursos financieros de Nueva España hacia las posesiones insulares y sus áreas dependientes no impidieron que la Corona iniciase en aquellos enclaves de la periferia imperial una dramática búsqueda de recursos propios, que pudiesen ser canalizados por las haciendas locales. ${ }^{22} \mathrm{El}$ objetivo no era otro que el de aliviar a las cajas novohispanas y redistribuir de manera algo más equitativa la pesada carga defensiva. En absoluto alterar los flujos de recursos intraimperiales vigentes desde el siglo XVI. ${ }^{23}$ Sabemos que Funes de Villalpando, el conde de Ricla, el máximo responsable en Cuba, estimó la cantidad que debería levantar la

21 Torres Ramírez, Bibiano: Alejandro O’Reilly en las Indias, Consejo Superior de Investigaciones Científicas, Sevilla, 1969, pág. 93.

22 Un excelente planteamiento general en Marichal, Carlos y Mantecón, Silvia: "Silver and Situados: New Spain and the Financing of the Spanish Caribbean in the Eighteenth Century", Hispanic American Historical Review, 74, 4, 1994, págs. 587-613.

23 La mejor síntesis sobre el tema se encuentra en Klein, H. S.: Las finanzas americanas del imperio español, Instituto de Investigaciones Históricas Dr. José María Luis Mora, México, 1994. 
Hacienda local cubana en torno a los 600.000 pesos. ${ }^{24}$ Con esta cifra se aspiraba a mantener una tropa veterana de más de 10.876 hombres y a ahorrar, en consecuencia, los 400.000 pesos de salarios que anteriormente se recibían de Nueva España para el pago de tropa. ${ }^{25}$ La cifra que se proponían recaudar se basaba en los cálculos del contador mayor Antonio Gelabert, un personaje clave en la definición de la estrategia reformista, que especulaba que la reorganización tributaria permitiría recaudar casi 600.000 pesos en la capital y 115.815 en el resto de la isla. A medio plazo, los cálculos del funcionario no se demostraron tan desacertados. Las recaudaciones en la isla alcanzaron los seiscientos mil pesos a partir de 1781, y sumaron casi el millón de pesos o lo superaron en las anualidades de 1782, 1792, 1796 y 1797-1799, antes de cerrar el siglo. En realidad, el dintel de los 600.000 pesos anuales se alcanzó ya en la primera mitad de la década de 1780, mientras que el millón de pesos no sería hasta los años 1795-1799, aunque las cifras disponibles siguen siendo demasiado gruesas. ${ }^{26}$ En los años siguientes, el descenso y la discontinuidad de los situados fue compensado con recaudaciones crecientes, superiores a los dos millones de pesos los quinquenios de 1805-1809, 1815-1819 y 18201824. ${ }^{27}$ Durante los años críticos de transición de una situación a otra, la real hacienda en La Habana recibió cantidades irrisorias comparadas con las de la última década del siglo XVIII, pero continuó ingresando pequeñas cantidades en concepto de las obligaciones de la Monarquía en Santo Domingo y en las diplomáticas en los Estados Unidos. Estas entradas de plata mexicana, por modestas que sean, se mantienen por lo menos hasta

24 Parcero Torre, Celia María: La pérdida de La Habana y las reformas borbónicas en Cuba, 1760-1773, Junta de Castilla y León, Madrid, 1998, págs. 237-238.

25 Hacia 1776, la guarnición de La Habana era de unos 5.650 soldados, pero en caso de necesidad podía llegar hasta los 7.000. Pérez Guzmán: La Habana. Clave..., pág. 178.

26 Utilizo las proporcionadas por John TePaske correspondientes a salidas de las cajas de Nueva España ("La política española en el Caribe durante los siglos XVIII y XIX", en Acosta, Antonio y Marchena, Juan (eds.): La influencia de España en el Caribe, la Florida y Luisiana (1500-1800), Instituto de Cooperación Iberoamericana, Madrid, 1983, págs. 61-87), y las de entradas contabilizadas en las de La Habana por Kuethe, Allan J.: "Guns, Subsidies, and Commercial Privilege: Some Historical Factors in the Emergence of the Cuban National Character, 1763-1815", Cuban Studies, 16, 1986, pág. 130.

27 Las cifras de recaudaciones de la Hacienda cubana fueron publicadas en el siglo XIX por Ramón de la Sagra y Jacobo de la Pezuela, con acceso directo ambos al personal y los libros contables de la poderosa Intendencia cubana. Utilizo las dos ya que, con ligeras variaciones, muestran las mismas tendencias. Del primero, me refiero evidentemente a la Historia económico-política y estadística de la Isla de Cuba ó sea de sus progresos en la población, la agricultura, el comercio y las rentas, Imprenta de las Viudas de Arazoza y Soler, La Habana, 1831, págs. 290-293 y 297; del segundo, el Diccionario geográfico, estadístico e histórico de la Isla de Cuba, t. III, pág. 273. 
$1820 .{ }^{28}$ Con todo, el riesgo de un colapso financiero de la hacienda cubana había sido salvado espectacularmente gracias a la conjunción de la revolución plantadora y las reformas hacendísticas que permitían canalizar parte de la renta agraria hacia las finanzas públicas de la colonia.

No cabe duda alguna de que este esquema político-financiero se orientaba hacia una distinción esencial de los recursos a disposición de la hacienda cubana: los fondos recibidos de Nueva España se destinarían a los trabajos de fortificación o se asignarían a las necesidades militares de la Corona en el espacio antillano y norteamericano, así como a otras obligaciones de importancia a las que prestaremos atención más adelante; mientras que los recaudados en la propia Isla se destinarían al pago de la tropa y a sostener los gastos de una administración de superior complejidad, entre otras obligaciones de la Monarquía en la colonia, como veremos a su debido momento. Sin pretender entrar ahora en los entresijos de la historia de los situados en La Habana, de sus desviaciones a menudo hacia objetivos poco acordes con los declarados (que es una cuestión de vital importancia) es importante destacar que el esquema de distribución de los recursos financieros que se impone en 1763-1764 perdurará hasta la quiebra misma de la hacienda virreinal, que John TePaske y Carlos Marichal describieron con tanta brillantez..$^{29}$ Aquellas cantidades eran, sin embargo, del todo insuficientes desde el punto de vista de las necesidades globales, aunque podían considerarse como una contribución importante para alcanzar el objetivo más restrictivo de sostener la nueva planta militar cubana, que se estimaba indispensable, y atender, al mismo tiempo, a las obligaciones de la Corona en todo el arco caribeño y del golfo de México. ${ }^{30}$

28 En el quinquenio de 1805 a 1809 recibió en total 778.600 pesos y en los cuatro años de 1815 a 1818 aquella cifra se había reducido a un total de 33.450, según testimonio de un documento manuscrito, fechado a 8 de marzo de 1869 , y preparado por los funcionarios del Archivo de Indias para el Ministerio de Hacienda, con las cifras de situados de todo el siglo XVIII y hasta aquella última fecha. Biblioteca Nacional (Madrid), Mss. 13.228, $\mathrm{n}^{\circ}$ 2. Los datos de 1820 proceden del Archivo Nacional de Cuba, Intendencia, 431, $\mathrm{n}^{\circ} 23$. Especifican que se mandaron 50.000 pesos a Santo Domingo "procedentes de Méjico".

29 TePaske, John Jay: "The Financial Desintegration of the Royal Government of Mexico during the Epoch of Independence", en Rodríguez, Jaime (ed.): The Independence of Mexico and the Creation of the New Nation, UCLA Latin American Center Publications, Los Ángeles, 1989, págs. 63 84; Marichal: La bancarrota del virreinato...

30 El esquema militar de 1764 se mantendrá hasta los años 1854-1855, cuando el riesgo de ataques anexionistas promovidos desde los Estados Unidos forzará a las autoridades españolas a establecer un nuevo esquema y a la supresión de las milicias de color, uno de los emblemas de las reformas de la época borbónica. 
Lo mismo sucedió en las otras dos posesiones insulares. En Puerto Rico el situado novohispano transferido a través de la Hacienda cubana resultó vital hasta el último momento. Según datos proporcionados por Darío de Ormaechea, intendente de Hacienda muchos años después, en 1847, en 1778 los gastos de la Hacienda puertorriqueña ascendían a 297.376 pesos mientras que las rentas propias no llegaban siquiera a cubrir el $16,14 \%$. En aquel año, el situado que recibieron las arcas de la Isla fue de 487.358 pesos. ${ }^{31}$ Diez años después, en 1788, el situado había ascendido hasta 695.050 pesos, mientras que los ingresos ordinarios de la hacienda local fueron de 196.526 pesos..$^{32}$ En los años que siguieron a la visita de O'Reilly a la isla, los gastos de defensa se mantuvieron muy cercanos a las previsiones del responsable del cambio de prioridades en el sistema de defensa. De 1769 a 1776, las cajas de la isla recibieron 1.296 .889 pesos, aunque el total efectivamente gastado en el mismo periodo fue de 1.079.151. ${ }^{33}$ En los años siguientes, hasta el fatídico de 1804, cuando se interrumpe la llegada de los situados desde Veracruz, las rentas propias de la Isla mostrarán una tendencia a un crecimiento sostenido: 215.967 pesos en $1791 ; 234.413$ en $1792 ; 389.972$ en 1795 y 315.642 en $1796 .{ }^{34}$ Progreso que evidencia las transformaciones internas de la economía de la Isla, pero sus volúmenes se alejan ciertamente de los que el situado garantizaba en función de los objetivos políticos de conjunto. Más revelador que estas cifras es el hecho de que, en 1815, los gastos se habían incrementado hasta 477.590 pesos, cuando las rentas propias lo habían hecho hasta 258.303. El incremento cierto de la capacidad recaudatoria de la Isla, cuyas razones exploraremos brevemente más adelante, no impidió que el déficit ascendiese a 219.287 pesos. ${ }^{35} \mathrm{El}$ ajuste entre la capacidad recaudatoria propia y el gasto militar era la única salida a una situación que se hizo crónica a partir de 1810, cuando la quiebra del sistema de situados es asumida por los liberales de las Cortes gaditanas como el punto de partida inexorable para una reforma de la base hacendística de la Isla.

31 Ormaechea, Darío de: "Memoria acerca de la agricultura, el comercio y las rentas públicas de la isla de Puerto Rico", Hacienda Pública Española, 1981, pág. 69.

32 Sonesson, Birgit: La Real Hacienda en Puerto Rico. Administración, política y grupos de presión (1815-1868), Monografías Quinto Centenario, Madrid, 1990, pág. 43.

33 Torres Ramírez, Bibiano: La Isla de Puerto Rico, 1765-1800, Instituto de Cultura Puertorriqueña, San Juan, 1968, págs. 230-231.

34 Córdova, Pedro Tomás de: Memorias geográficas, históricas, económicas y estadísticas de la Isla de Puerto Rico, Editorial Coquí, San Juan, 1968, t. III, págs. 62-66.

35 Ormaechea: "Memoria acerca...", pág. 406. 
El caso filipino es bastante más complicado. La colonia asiática dependía parcialmente de la llegada del situado novohispano, aunque este no puede parangonarse con el que recibían las posesiones del Caribe..$^{36} \mathrm{~A}$ pesar de la diferencia de magnitudes, la posición de Manila como plaza fuerte y puerto de gran importancia militar era muy similar a la de $\mathrm{La}$ Habana y seguía siendo, en el último tramo del siglo XVIII, un elemento de relevancia extraordinaria para la defensa de la retaguardia del Imperio. La toma de La Habana por los barcos de la East India Company, a principios de octubre de 1762, puso en evidencia la debilidad de las fortificaciones de la ciudad y la precariedad de los apoyos sociales con que contaba el aparato colonial. ${ }^{37} \mathrm{Al}$ igual que había sucedido en La Habana, el golpe de mano británico en Manila desembocó en un cambio de lealtades de diversos grupos sociales. ${ }^{38}$ Dos de ellos no resultaron en absoluto sorprendentes para los responsables del gobierno de la colonia, el tercero no entraba en sus planes. En efecto: la colaboración de los chinos del Parián (el barrio donde vivían confinados en la ciudad-puerto desde el levantamiento y masacre de 1639) con los invasores y los levantamientos campesinos de Pangasinan, en el área tagala, y el de Diego Silang, en Ilocos, entraban en el terreno de lo posible y pensable, ya que había elementos de continuidad evidentes con revueltas o actitudes contrarias al dominio español en periodos anteriores. ${ }^{39}$ La deslealtad de la Iglesia a la Monarquía era otra cosa, aunque es poco dudoso que los planes de reforma de los derechos de las misiones (el cobro completo del tributo de naturales) y de la parte del tributo personal que se apropiaban las parroquias (que en muchas provincias filipinas estaban en manos de las órdenes de regulares, desde fines del siglo

36 Sobre esta cuestión, Bauzon, Leslie E.: Deficit Government. Mexico and the Philippine Situado, 1606-1804, The Centre for East Asian Cultural Studies, Tokyo, 1981.

37 No existe ningún estudio de referencia sobre la toma de la ciudad por los británicos, pero pueden consultarse las obras siguientes: Cushner, Nicholas P. (ed.): Documents illustrating the British Conquest of Manila, 1762-1763, Royal Historical Society, Londres, 1971; Tracy, Nicholas: Manila Ransomed. The British Manila in the Seven Years War, University of Exeter Press, Exeter, 1995.

38 Sobre la toma de Manila, Costa, Horacio da: "The siege and Capture of Manila by the British, september-october of 1762", Philippine Studies, 10, 4, 1962, págs. 607-653.

39 Sobre la revuelta de Pangasinan, de Mendoza Cortés, Rosario: Pangasinan, 1572-1800, New Day Publishers, Quezon City, 1991, págs. 169-222. La de Diego Silang fue estudiada por Routledge, David: Diego Silang and the Origins of Philippine Nationalism, Philippine Center for Advanced Studies, University of the Philippines, Quezon City, 1979. Sobre la minoría china, sigue siendo indispensable el trabajo de Wickberg, Edgar: The Chinese in the Philippine Life, 1850-1898, Yale University Press, New Haven, 1965. Sobre las represalias contra la minoría china después de la guerra, Escoto, Salvador: "Expulsion of the Chinese and Readmision to the Philippines: 1764-1779", Philippine Studies, 47, 1999, págs. 48-77. 
XVI) que circulaban por las oficinas de la Audiencia manileña, despertasen la desconfianza de la Iglesia en la administración colonial de Manila. El problema, entonces, era muy parecido al que los reformistas españoles habían encontrado en Cuba: reforzar el sistema defensivo ya existente y reorganizar el ejército de la colonia. Pero el diseño de una estrategia defensiva que partiese de las lecciones de la guerra correspondió, en la colonia asiática, a las instituciones tradicionales de gobierno. El mando político y militar corresponderá al vasco Simón de Anda y Salazar, capitán general y gobernador del archipiélago entre el año 1770 y el de su muerte en 1776, que había sido el artífice de la resistencia contra los ingleses y contra los sublevados en general. ${ }^{40}$ En el plano de la estrategia, el hombre clave será otro alavés, Francisco Leandro de Viana, fiscal de la Audiencia de Manila desde 1758 y autor de los más brillantes memoriales sobre el archipiélago. ${ }^{41}$ En ellos, el futuro conde de Tepa desarrollará una compleja posición que atendía tanto a elementos estrictamente militares, como a políticos, institucionales y, por supuesto, hacendísticos. En lo estrictamente militar el proyecto del esforzado funcionario borbónico apostaba por la reedificación de Manila y Cavite (el lugar de los astilleros de la Armada en la misma bahía), el incremento de los efectivos de la Marina para garantizar la navegación transpacífica y la reorganización del Ejército. ${ }^{42}$ Para el fiscal de la Audiencia era indispensable mantener una guarnición de 3.000 hombres en Manila y unos mil más repartidos entre las provincias filipinas al mando de los alcaldes mayores, la primera autoridad en todos los campos de la administración. ${ }^{43}$ No todas las ideas de Viana fueron llevadas a la práctica, y él

40 Martínez Salazar, A.: Alaveses en América y Filipinas (1700-1825), Diputación Foral de Álava, Vitoria, 1988.

41 Sobre Viana existen dos trabajos inéditos que pueden consultarse. La tesis doctoral de Viana Pérez, Francisco: Francisco Leandro de Viana: un togado en Indias al servicio del Rey, Universidad del País Vasco, Vitoria, 1994; y la tesis de licenciatura de Llobet, Ruth de: Francisco Leandro de Viana: Análisis de una visión reformista aplicada a las Islas Filipinas, Universidad Pompeu Fabra, Barcelona, 2000.

42 Demostración del mísero, deplorable estado de las Islas Filipinas; de la necesidad de abandonarlas o mantenerlas con fuerzas respetables; de los inconvenientes de lo primero y ventajas de lo segundo; de lo que pueden producir a la Real Hacienda, de la navegación, extensión y utilidades de su comercio. Con reflexiones que convencen la utilidad de formar una compañía, bajo la real protección para hacer feliz y gloriosa la Monarquía española. Y privar a sus enemigos de las ganancias con que la destruyesen en paz y en guerra, Manila, 10 de julio de 1766. Biblioteca de los Agustinos Filipinos, Valladolid.

43 Y cultivando la alianza con los grupos regionales que apoyaron siempre al poder español. Es el caso de los pampangos, que formaban, y siguieron formando, parte de las milicias. Sobre la región y su fuerte interacción en todos los órdenes con los españoles, Larkin, John A.: The Pampangans. Colonial Society in a Philippine Province, University of California Press, Berkeley, 1972. 
mismo las matizó en textos posteriores. ${ }^{44}$ Es más, algunas de sus propuestas fueron eficazmente criticadas por otros personajes de relieve o tuvieron que ser corregidas por los administradores en los años posteriores, aunque sirvieron ciertamente como orientación fundamental para la reconstrucción del poder español tras el descalabro de 1762. Para hacer efectivo el programa de edificaciones militares que entonces se emprende (que, entre otras cosas, comportó veinte años de trabajos de fortificación en Manila y Cavite), la hacienda filipina recibió fondos desde Nueva España de manera discontinua durante la última década del siglo XVIII, muy por encima de lo que hasta entonces era habitual. Los últimos fondos de situados de procedencia novohispana contabilizados por la Real Hacienda en Manila fueron los siguientes: de 1789 a 1792, 584.626 pesos; de 1800 a 1802, 819.249 ; y 322.050 en $1804 .{ }^{45}$ Como sucedió en los otros contextos que estamos estudiando, el virrey de Nueva España advirtió en 1804 sobre el fin de las remesas que se habían estado enviando secularmente. Los últimos fondos recibidos se pueden fechar en 1810, aunque para aquel entonces los situados eran ya algo residual. En aquella situación crítica, cuando la colonia queda como un barco a la deriva por la insurrección del virreinato, las finanzas públicas filipinas disponían de cartas que jugar y evitaron el previsible colapso.

Los tres contextos insulares que hemos analizado presentan similitudes notables, a pesar de las diferencias de peso específico y de la naturaleza muy distinta de sus estructuras sociales y de su economía. Los tres enclaves eran deficitarios desde el punto de vista hacendístico. Esta es una realidad innegable y explica, por sí sola, el flujo constante de recursos financieros desde las arcas novohispanas hasta la periferia insular del sistema imperial. Puntualizado este hecho, debe matizarse de inmediato con algunas observaciones fundamentales. La primera, que las Reales Haciendas de Cuba, Puerto Rico y Filipinas eran deficitarias por su obligada inserción en la estrategia imperial y, en particular, en la que se impone tras la Guerra de los Siete Años y el Tratado de París. La estrategia de defensa

44 Por ejemplo por Francisco Javier Salgado, un personaje tan interesante como empresario en el añil y la minería como importante en la defensa de la colonia frente a los británicos. Adversario acérrimo del fiscal, criticó los cálculos excesivamente optimistas de los recursos internos filipinos en los que se basaban las previsiones de nuevos ingresos fiscales de Viana. Sobre Salgado, deben consultarse las esclarecedoras páginas de Legarda, Benito J., Jr.: After the Galleons. Foreign Trade, Economic Change and Entrepreneurship in the Nineteenth-Century Philippines, Ateneo de Manila Press, Quezon City, 1999, págs. 64-71.

45 AGI, Filipinas, Gobierno, 871. 
total que se diseñó en aquella coyuntura primó, como ya vimos, la fortificación de las principales plazas fuertes y la formación de un ejército con capacidad teórica para el control sobre el territorio y sobre la sociedad local. Aquellos supuestos implicaban cambiar muchas cosas del ordenamiento institucional y hacendístico y, en consecuencia, del pacto colonial hasta entonces vigente, hasta el punto de comprometer la rentabilidad misma del Imperio. En segundo lugar y contra lo que se argumenta en parte de la literatura reciente sobre estos temas, las reformas se llevaron a la práctica sobre un terreno poco maduro para las graves extorsiones fiscales que le eran implícitas, una afirmación que no comporta ignorar, en absoluto, los cambios internos que se habían producido en cada uno de ellos antes del annus horribilis de 1762 ni dejar de valorar su trascendencia a medio plazo. Además, la escasa lealtad de los hacendados cubanos o de la Iglesia filipina cuando la invasión británica derribó el orden natural de las cosas mostró, a las claras, cuán poco propensos a realizar sacrificios pecuniarios por la Corona eran algunos sectores de los grupos dirigentes de los enclaves insulares. En consecuencia, imponer las drásticas prioridades de los equipos gobernantes de Carlos III implicaba emprender reformas radicales de orden económico, institucional y fiscal en los tres enclaves o incrementar la ayuda financiera desde Nueva España. O las dos cosas a la vez, que es lo que efectivamente ocurrió. En tercer lugar y justamente por la premura y radicalidad del empeño de los gobernantes, la reforma de la base tributaria en cada una de las tres posesiones se resolvió en un do ut des entre sus grupos dirigentes y la administración colonial, pero debe destacarse que no existían, a priori, los recursos que pudiesen ser canalizados por las viejas figuras tributarias o por aquellas que se forjasen con el ánimo de levantar otros hasta entonces inéditos. En conclusión: el esfuerzo militar de la Monarquía debería descansar sobre la capacidad del gran Virreinato del que dependían aquellas posesiones para proporcionar, vía situados, los recursos indispensables, aunque Cuba, Puerto Rico y Filipinas aportasen sumas considerables, tal y como efectivamente sucedió hasta los primeros años del siglo XIX, en plena crisis de la estabilidad financiera del Imperio. Hasta 1804, las tres posesiones fueron receptoras netas de recursos de manera continuada. Este hecho incontrovertible tiene, sin duda, una importancia crucial a la hora de entender su contraste con la crisis latente en Nueva España, que se sitúa en otro polo como prestadora neta que era. A medio plazo, más allá de la quiebra de la hacienda del Virreinato, las dos Antillas y Filipinas encontraron los recursos propios para sostener una hacienda ali- 
gerada de aquellas pesadas obligaciones militares sin salir del dominio español. No es fácil responder adecuadamente sobre el grado de responsabilidad de las reformas borbónicas en el desarrollo de la nueva situación. Acercarse a la respuesta exige probablemente dos cosas: liberar la idea y el concepto mismo de reformas borbónicas de una cierta carga totalizadora excesiva; y, en segundo lugar, insertarlas en procesos más amplios, económicos y políticos, que permitan reflexionar sobre las dinámicas locales, más allá de la lógica imperial y postimperial de conjunto.

\section{Azúcar y tabaco}

Movilizar recursos susceptibles de incrementar las recaudaciones de las finanzas públicas de las tres colonias se convirtió, en las posesiones insulares de la periferia del Imperio, en un asunto de algunos pocos y selectos productos de la agricultura tropical. En pocas palabras, en un asunto de tabaco y azúcar, aunque para Puerto Rico, a largo plazo, y para Cuba, hasta los años treinta, debemos añadir el café. Una cuestión de producción y comercio, orientados e interferidos, ambos por igual, por las disposiciones de política económica que derivaban de los cambios fiscales que la Monarquía se había visto precisada a introducir para tratar de digerir el décalage abismal ente sus necesidades efectivas y la capacidad de aquellas sociedades de generar recursos que podían ser movilizados por el fisco. En este apartado nos ocuparemos de este último punto. Esto es: de cómo la reforma de la fiscalidad en Cuba y Filipinas (con algunas observaciones comparativas para el caso de Puerto Rico) se resolvió en relación a las capacidades locales, tratando de deshacer algunos equívocos que surgen de lecturas post facto no siempre convincentes.

El primero de ellos se refiere a la naturaleza del proceso reformista en Cuba, un punto crucial, como vimos, como lugar de experimentación del propio proyecto reformista. Los trabajos de Allan Kuethe señalaron con rigor uno de los aspectos claves del proceso reformista en su lógica más profunda: la negociación entre la burocracia imperial y una selecta representación de los intereses criollos para establecer las bases de un nuevo pacto colonial, en el que la aportación de la economía cubana a la defensa imperial fuese de más entidad. ${ }^{46}$ La sustancia del acuerdo no resulta difícil

46 Cuba, 1753-1815. Crown, Military and Society, págs. 68-77. 
de sintetizar: la refundición sobre los derechos de los principales renglones de exportación - en los más estrictos términos, el azúcar, los aguardientes y las mieles de caña - a cambio de un conjunto de medidas de liberalización del comercio exterior y, cuestión fundamental, de la importación de mano de obra esclava ${ }^{47}$ Por lo tanto, la alcabala sobre los frutos (del 4 al 6\% ad valorem), la liberalización del área comercial de Barlovento en 1765, las incorporaciones posteriores de 1770 y 1774, el Reglamento de Libre Comercio de octubre de 1778 y los permisos de neutrales posteriores, y la definitiva libertad de importación de africanos (de negros bozales) por las reales cédulas de 28 de febrero de 1789 y de 24 de noviembre de 1791, fueron las tres patas de una reorientación completa de la economía cubana, en particular de la relación entre la economía local y el comercio internacional, libre o con constricciones monopolistas de corte mercantilista tardío. ${ }^{48}$ Estas son las líneas generales del proceso de ajuste entre la sociedad local y el aparato imperial, a las que se suele añadir una narración larga y penosa del via crucis de las autoridades metropolitanas, bebiendo uno a uno la amarga pócima de su rendición a las presiones de una poderosa clase de hacendados azucareros. La realidad era algo más compleja, pero sólo una lectura atenta de los delicados equilibrios entre la visión de los funcionarios reformistas y el desarrollo del proyecto de los azucareros podrá dar cuenta de los términos globales de la evolución de la economía y la política de la isla en el último tramo del Imperio.

Dos cuestiones decisivas deben ser mencionadas en este intento de revisión. La primera de ellas se refiere a la estrecha conexión entre la reforma comercial y la recuperación, por parte de la Hacienda metropolitana, de una parte muy importante del flujo llegado a la Isla vía situados. La segunda, nos remite de nuevo a las intrincadas estructuras de la política tributaria y a su formalización monetaria: el desarrollo en paralelo a los cambios que permitieron el ascenso imparable del sector azucarero del estanco tabaquero. El primer punto ha sido planteado por Josep M. Delgado, en los términos siguientes. La financiación del gasto en las regiones del Imperio

47 Kuethe, Allan J. e Inglis, Douglas C.: "Absolutism and Enlightened Reforms: Charles III and the Establishment of the Alcabala, and Commercial Reorganization in Cuba", Past and Present, 109, 1985, págs. 118-143.

48 La mejor síntesis del cambio legislativo en Delgado, Josep M.: "El modelo catalán dentro del sistema de libre comercio", en Fontana, Josep y Otros: El comercio libre entre España y América Latina, 1765-1824, Fundación Banco Exterior, Madrid, 1987, págs. 53-70. Para los casos de Nueva España y Cuba, Kuethe, Allan J.: "La desregulación comercial y la reforma imperial en la época de Carlos III: los casos de Nueva España y Cuba”, Historia Mexicana, 1991, 2, págs. 265-292. 
debía ir necesariamente acompañada de la formación de incentivos económicos capaces de dinamizar la economía de las áreas subvencionadas del imperio, para que ésta fuera capaz de generar, a medio plazo, los recursos necesarios para reducir significativamente su dependencia de las remesas del situado. La articulación entre entradas de plata fuerte en Cuba, por la vía del situado, y salidas, como pago de mercancías introducidas a través del comercio libre a partir de 1765, garantizaba, además, que las inversiones en pesos fuertes de cuño mexicano, hechas en la financiación de las defensas imperiales en la isla, tenían por destino final los puertos habilitados de la metrópoli. ${ }^{49}$ El problema era que este modelo de circulación monetaria, basado en el drenaje constante de la plata fuerte americana en dirección hacia España, entró en contradicción con el desarrollo de la nueva agricultura de plantación a partir de finales de los años ochenta, cuando la necesidad de hacer frente a las fuertes inversiones de la industria azucarera -costo de esclavos y de bienes de equipo- chocó con la inexistencia de un ahorro interno susceptible de ser movilizado para financiar operaciones de adquisición de capital fijo que sólo podían financiarse a largo plazo. ${ }^{50}$ Este importante trasunto de los cambios institucionales y políticos que se producen en 1764-1765 no debe quedar en segundo plano. ${ }^{51}$

En los años anteriores a la invasión inglesa las opiniones más extendidas sobre la naturaleza y el futuro de la economía cubana apuntaban hacia un modelo de contrapunto, casi dual, entre el tabaco y el azúcar, con el añadido de algunas otras producciones agrícolas en un claro segundo plano y de una modesta minería extractiva por desarrollar..$^{52}$ Esta interpretación de la estructura económica de Cuba debe situarse sobre el fresco bien conocido de las actividades de hacendados y campesinos tradicionales y con una fuerte base de autosuficiencia relativa, muy caribeña, y ganadera (de contrabando de carne y cueros con las islas de monocultivo azucarero de otras potencias), que caracterizaba a la mitad oriental de la isla hasta que la expansión azucarera de mediados de siglo XIX no empezó a variar el paisaje agrario de

49 Para una etapa posterior pero con indicaciones de gran relevancia para estas cuestiones, Stein, Stanley J.: "Caribbean Counterpoint: Veracruz vs. Havana. War and Neutral Trade", en Chase, Jeanne (ed.): Géographie du capital marchand aux Amériques, 1760-1860, París, 1987, págs. 21-44.

50 Delgado, Josep M.: "Situados y comercio libre (1762-1776). La gestación de un sistema fiscal imperial", Illes i Imperis, 2003, 8 (en prensa).

51 Para un periodo anterior, es imprescindible la consulta del libro de Stein, Stanley J.: Silver, Trade, and War. Spain and America in the Making of Early Modern Europe, The Johns Hopkins University, Baltimore, 2000.

52 Esta fue la interpretación clásica de Fernando Ortiz en Contrapunteo cubano del tabaco y del azúcar, Ariel, Barcelona, 1973. (La primera edición es de 1940). 
la región..$^{53}$ La visión más completa de la economía cubana a mediados del siglo XVIII, antes de la invasión, es la que nos dejó Bernardo de Urrutia y Matos. ${ }^{54}$ Este personaje era funcionario de la Real Compañía de Comercio de La Habana, entre cuyos objetivos figuraba, desde su erección en 1741, el asiento suministrador de tabacos para la fábrica de Sevilla. ${ }^{55}$ El trabajo pionero y bien informado de Urrutia establecía con claridad meridiana el lugar central que ocupaba aquel producto en la estructura económica de la isla: "No es de creer que, sin el tabaco, pueda contarse sobre el azúcar y cueros, porque aunque los ingenios y los ganados se multipliquen quebrará todo, en faltando el nervio principal del comercio". ${ }^{56}$

Para Urrutia la lógica del desarrollo era clara: primero, el tabaco, después el azúcar y, en tercer lugar, el ganado. ${ }^{57}$ Medio siglo más tarde, las cosas habían cambiado mucho, pero aquella dualidad productiva heredada seguía siendo objeto de discusión entre los tratadistas que se ocupaban del futuro de la isla. Se trataba, sin embargo, de un debate muy peculiar, duramente condicionado por las contingencias del pulso entre los hacendados del azúcar y el poder colonial.

Por esta razón, los grandes textos en defensa del mundo de "sacarócratas", como les denominó Manuel Moreno Fraginals, de Francisco Arango y Parreño y Antonio del Valle Hernández, no pueden interpretarse como una descripción sin más de la realidad económica cubana en aquel momento de cambio. El más conocido del segundo de ellos, que fue secretario durante veinticinco años de la Junta de Gobierno del Real Consulado de Agricultura, Industria y Comercio de La Habana, describió la economía cubana gravitando en torno a la producción azucarera. Para él, el reto fun-

53 La noción de "autoconsumo" como pauta definitoria de la Cuba oriental es de Pérez de la Riva, Juan: "Una Isla con dos historias", incluido en El barracón y otros ensayos, Crítica, Barcelona, 1978, págs. 175-176. La tendencia al desarrollo de campesinados en los márgenes y vis à vis a la plantación esclavista y a las grandes unidades económicas, fue hábilmente planteada por Craton, Michael: "Property and Propiety. Land Tenure and Slave Property in the Creation of a British Slave West Indian Plantocracy, 1612-1740" y "Proto-Peasant Revolts? The late slave Rebellions in the British West Indies, 1816-1832", en Empire, Enslavement and Freedom in the Caribbean, James Currey Publishers, Oxford, 1997, págs. 68-103 y 282-305; para una etapa posterior, Holt, Thomas C.: The Problem of Freedom.

Race, Labor, and Politics in Jamaica and Britain, 1832-1938, The Johns Hopkins University Press, Baltimore, 1992, págs. 146-168.

54 Cuba. Fomento de la Isla. 1749, Primer estudio geo-económico de la Isla, editado por Leví Marrero, Ediciones Capiro, Puerto Rico, 1993.

55 Gárate Ojanguren, Montserrat: Comercio ultramarino e Ilustración: la Real Compañía de La Habana, Departamento de Cultura del Gobierno Vasco, Donostia, 1993, págs. 56-60.

56 Cuba. Fomento de la Isla. 1749..., pág. 91.

57 Ibídem, págs. 42-43. 
damental era asegurar un abastecimiento regular y barato de esclavos, con una casi nula atención (a excepción del café) a los otros sectores de la agricultura de la Isla. ${ }^{58} \mathrm{El}$ tabaco brilla por su ausencia en la soflama fisiocrática del ilustrado secretario del Consulado. No es el caso de Arango y Parreño, colaborador íntimo del anterior. El gran habanero habló mucho de tabaco y mucho más todavía del azúcar, pero su presentación del lugar de uno y otro cultivo ilumina a la perfección las razones de un tratamiento francamente desigual. Como es bien conocido por los historiadores, su escrito de mayor relevancia, el compendio de su posición intelectual, es el Discurso sobre la Agricultura de La Habana y medios de fomentarla del año 1792, en sintonía con el espectacular despegue del sector azucarero. ${ }^{59}$ Toda la armazón intelectual del texto de Arango está pensada para situar al sector azucarero en el centro de las expectativas de crecimiento económico cubano y, nolens volens, para hacerlo receptor de la protección de la administración colonial, en la que él mismo y sus colaboradores fueron parte tan activa hasta la tercera década del siglo XIX. Y, por lo general, se ha leído exclusivamente en esta perspectiva, ignorando sugerencias muy relevantes y sobreentendidos de enorme significado. Ciertamente que el núcleo central de su argumento es idéntico al de Antonio del Valle; en síntesis: que la isla sólo podía ser agricultora, que su futuro estaba ya identificado al del azúcar y que éste no era viable sin esclavos y libertad comercial. ${ }^{60}$ Un punto al que se refieren por igual Arango y Del Valle, especialmente relevante para la historia que estamos contando, es la preocupación por ambos expresada de la dificultad de formación de capitales en el sector azucarero, condición de posibilidad del tamaño del ingenio y, por lo tanto, de su competitividad en el mercado internacional al que estaba accediendo gracias a los cambios en la política arancelaria. ${ }^{61}$ Para el segundo de ellos, era indispensable atraer capitales desde Nueva España, desviando hacia la agricultura

58 Valle Hernández, Antonio del: Sucinta historia de la situación presente de esta colonia. 1800, prologado por Juan Pérez de la Riva, Editorial de Ciencias Sociales, La Habana, 1977.

59 Arango y Parreño, Francisco de: "Discurso sobre la Agricultura de La Habana y medios de fomentarla”, en Obras de..., Ministerio de Educación, La Habana, 1952, págs. 114-162.

60 Por "agricultora" estos fisiócratas-smithianos entendían la plantación con esclavos al estilo de las Antillas de los otros países europeos. Ni más ni menos. Lo que los historiadores económicos del presente explican eufemísticamente como una opción por la especialización exportadora.

61 El coste medio del esclavo de procedencia africana puede computarse en torno a los 300 pesos, antes de su abaratamiento posterior gracias a las liberalizaciones de 1789-1793 que permitieron la formación de un sector negrero en La Habana y en los puertos de la periferia peninsular. Esto significa que unos veinte millones de pesos fuertes fueron invertidos, entre 1789 y 1800, para financiar las dotaciones de los ingenios del occidente cubano. Véase la nota 30. Sobre los precios de los esclavos 
del occidente de la Isla parte del flujo de plata fuerte movilizada por el libre comercio. ${ }^{62}$ La reflexión en paralelo, anterior de hecho, de Arango y Parreño es más reveladora, si cabe, de las complejas interacciones entre la política militar y fiscal, la espectacular emergencia del sector azucarero en las décadas de 1770-1780. ${ }^{63}$ Entre lo uno y lo otro, se afirmó la importancia decisiva de la plata fuerte del continente recibida en la isla (y de los mecanismos para desviarla hacia el mundo del azúcar) en el punto álgido de las reformas en la financiación de los primeros ingenios de tamaño realmente competitivo en términos internacionales. ${ }^{64}$ Conviene citar a Arango y Parreño en este importante punto: "Treinta y cinco millones de pesos que entraron para la subsistencia del ejército, después de llenar el vacío de la macuquina, envilecieron el numerario, dieron un precio exorbitante a todas las cosas vendibles y proporcionaron recursos a los mismos azucareros para recompensar con ventajas el estanco de sus cosechas. ¡Ojalá que a tan-

bozales y criollos en el mercado cubano, Bergad, Laird W., Iglesias García, Fe y Barcia, María del C.: The Cuban Slave Market, 1790-1800, Cambridge University Press, Cambridge, 1995, pág. 48. Sobre aquella etapa del mundo del azúcar, Tornero Tinajero, Pablo: Crecimiento económico y transformaciones sociales. Esclavos, hacendados y comerciantes en la Cuba colonial (1760-1840), Ministerio de Trabajo y Seguridad Social, Madrid, 1996.

62 "Para que siga haciendo la agricultura grandes progresos, es preciso invertir en ella nuevos fondos, porque es proposición indispensable, que el cultivo no tiene aquí más limites, que la cantidad de los fondos que en el se empleen, de modo que si recibiera en poco tiempo la colonia nuevos y grandes capitales, crecerían sus labores en la misma proporción. Ha comenzado ya el comercio de VeraCruz a abrir los ojos sobre esta clase de especulaciones, y a querer partir ganancias con el de La Habana. Es de creer, que mientras el superior gobierno de nuestra España no se deje sorprehender, no será vana la licencia que ha concedido el Rey, para que aquellos vecinos puedan emplear sus fondos en frutos de esta Isla. Mas era menester que se estendiese este movimiento hasta aquella porción de caudales casi muertos, que duermen en el Reyno, ó solo producen un cortísimo interés de un $3 \%$ a tiempo que acá, sin quebrantarse nuestros fondos territoriales, podemos dar por ello, seis, siete, ocho y hasta diez.” Valle Hernández: Sucinta historia de la situación..., págs. 72-73.

63 Sobre las primeras etapas del sector azucarero moderno, sigue siendo indispensable el gran libro de Moreno Fraginals, Manuel: El ingenio. Complejo económico social cubano del azúcar, Editorial de Ciencias Sociales, La Habana, 1978; también, Marrero, Leví: Cuba: economía y sociedad. Vol. IX: Azúcar, ilustración y conciencia (1763-1868), Editorial Playor, Madrid, 1983.

64 La dimensión del ingenio debe medirse por el número de esclavos, el componente esencial de su capital fijo. Como establecía Del Valle Hernández: "la verdadera escala de la riqueza de los fondos rurales no es tanto la cantidad de tierra, como el número de brazos hábiles." (Sucinta historia de la situación..., pág. 78). Y en aquella coyuntura, un ingenio con capacidad para competir era una unidad de entre 200 y 300 trabajadores forzados. Raramente se supera, hasta la llamada "primera danza de los millones" (1820s) por Manuel Moreno Fraginals, la última cifra. En el momento que Arango escribe el Discurso, esclavos y utillaje se compraban con preferencia en las West Indies inglesas, y se pagaban con plata fuerte. Un ingenio de dimensiones aceptables exigía, entonces, una importante inversión de capital. Y el éxito del inversionista dependía enormemente de las contingencias del comercio internacional, pues no es bastante suponer una demanda muy elástica, para que se mantuviese un determinado nivel de precios, como se verá en la segunda década del siglo XIX. Era muy vulnerable, por esta razón, a la coyuntura, hecho que no dejaba de afectar a la lealtad de los plantadores hacia sus monarcas respectivos. 
tos bienes se hubiese unido la ventaja de saber aprovecharlos! Pero cuando volvió el ejército, cuando nos vimos solos y ajustamos nuestras cuentas, fue cuando conocimos que apenas quedaban en nuestro poder el diezmo de la riqueza que allí se había derramado. Las demás se escaparon al extranjero en cambio de bagatelas, y lo peor es que aun este corto resto, la mayor parte se había empleado en el fomento de haciendas que no daban los costos cuando faltó la abundancia de consumidores. En este estado tomaron su antiguo curso las cosas y los agricultores de los ramos de extracción encontraron sus haciendas sin adelanto alguno, desprovistas de negros y escasas de todo utensilio. Tenían algún numerario de la inundación pasada, y se deshacían por emplearlo en mejora de sus ingenios, creyendo que estas haciendas seguirían prósperamente." ${ }^{\prime 65}$ Constatada esta situación, tan magníficamente descrita por el habanero, la liberación de las exportaciones, la libertad de pagos en moneda fuerte para adquirir esclavos y bienes de equipo para los ingenios, el abaratamiento del precio de compra de la mano de obra forzada procedente de África y la lucha por el control de la política fiscal se convirtieron en la esencia del programa plantador, al que el mismo Arango siguió dando forma hasta la tercera década del siglo XIX. ${ }^{66}$

No es esta la ocasión para una discusión a fondo sobre la participación de ambos productos de la agricultura tropical en el producto interior de la isla, algo que merecería sin duda un estudio pormenorizado que ahorrase discusiones al respecto. ${ }^{67}$ Tampoco tendría sentido alguno replante-

65 Ibídem, págs. 120-121.

66 Sobre la financiación de las compras, ver García, Gloria: "La exportación de moneda y el comercio de esclavos (Cuba, 1760-1800)", Rábida, 11, 1992, págs. 73-81. Sigue faltando una buena biografía de Arango. Es inevitable, entonces, seguir consultando la de Ponte Domínguez, Francisco J.: Arango Parreño: estadista colonial cubano, Imprenta Molina y Compañía, La Habana, 1937. Véase el artículo reciente de Tomich, Dale: "The Wealth of Empire: Francisco Arango y Parreño, Political Economy, and the Second Slavery in Cuba", Comparative Studies in Society and History, 45, 1, 2003, págs. 4-27. Sobre la libertad de exportación de moneda véase Serrano, Violeta: La Intendencia de Hacienda en Cuba, Instituto de Ciencias Históricas, La Habana, 1983, pág. 52.

67 Abundan las descripciones de la transformación económica cubana a partir de la evidencia aplastante y exitosa de su especialización azucarera. No se trata, a mi parecer, de contradecir lo obvio o, lo que todavía sería más absurdo, negar capacidad de penetración y análisis a estudiosos como Alexander von Humboldt o Ramón de la Sagra, sino de plantear las cosas en un marco que incluya algunas variables claves. O que ponga en duda variables aparentemente incontrovertibles, como la de la autofinanciación de la industria azucarera desde su inicio. De no haber excluido tan a conciencia a Manuel Moreno Fraginals de entre sus fuentes, quizás las páginas de Pedro Fraile Balbín y Richard y Linda Salvucci no resultarían tan convencionales. Me refiero al trabajo: "El caso cubano: exportaciones e independencia", en Prados de la Escosura, Leandro y Amaral, Samuel (eds.): La independencia americana: consecuencias económicas, Alianza, Madrid, 1993, págs. 80-101. En una línea parecida, el de Cortés Conde, Roberto: "Cuba: Sugar a Plantation Economy", The First Stages of Modernization in Spanish America, Harper and Row, New York, 1974, págs. 29-56. 
ar la importancia que adquiere la producción azucarera en aquellas mismas décadas, a pesar de que los niveles de partida son poco claros, antes de disponer de las primeras cifras fiables del comercio exterior cubano. ${ }^{68}$ Pocas dudas plantea el reconocimiento del acicate extraordinario que significó la ruina de Saint Domingue francés entre 1791 y 1793 (aunque no sería fácil construir un modelo contrafactual que aislase su impacto sobre los precios), a partir del cual crece a unas tasas anuales de en torno al 40\%. ${ }^{69}$ Presentados los datos de otra manera: si en 1759 eran 89 las unidades azucareras, en 1792 eran 227, 305 en 1802 y 625 en $1817 .{ }^{70}$ En términos de producto: la producción azucarera cubana (sin tomar en consideración las mieles y los alcoholes de caña) pasó de 7.968 toneladas métricas de media quinquenal en los años $1777-1781$ a $8.559,8$ en 17821786, a 13.752 en el siguiente, a 17.818 en $1792-1796$, a 28.722 en los años 1797-1801, a 37.186 en 1802-1806 y 38.860 los años 1807-1811, descendiendo ligeramente a 38.506,2 los cinco siguientes, para volver a subir hasta 51.628 en 1817-1821 y de nuevo a 66.976 en 1822-1826, y hasta $86.381,2$ los cinco siguientes, a 106.109,2 en 1832-1836, a 141.185 en el quinquenio 1837-1841 y hasta 177.480 en el siguiente, de 1842 a $1846 .{ }^{71} \mathrm{La}$ espectacularidad de la expansión azucarera (se multiplicó por más de veinte en el periodo cuyas cifras acabamos de revisar) no admite, por tanto, paliativos de ningún tipo. En estrecha correlación con ella, los plantadores adquieren un protagonismo creciente frente al viejo comercio

68 De interés para este punto, el libro de McNeill, John Robert: Atlantic Empires of France and Spain. Louisbourg and Havana, 1700-1763, The University of North Carolina Press, Chapel Hill, 1985.

69 Las cifras fueron publicadas en su momento por Alexander von Humboldt y Ramón de la Sagra. Han sido compendiadas recientemente por Lavallé, Bernard y otros: La América española (1763-1898). Economía, Editorial Síntesis, Madrid, 2002, pág. 243. Sobre esta etapa del desarrollo de la plantación, véase el libro de Tornero Tinajero: Crecimiento económico y... Del mismo autor: "Ingenios, plantación y esclavitud: una aproximación al estudio de los esclavos en los ingenios cubanos (1760-1821)", Anuario de Estudios Americanos, 1986, XLIII, págs. 35-68, y "Emigración, plantación y esclavitud", Anuario de Estudios Americanos, XLIV, 1987, págs. 229-280.

70 Tomo estos datos, muy borrosos si cotejamos distintas fuentes, del trabajo de García Rodríguez, Mercedes: “Ingenios habaneros del siglo XVIII”, Arbor, 547-548, 1991, pág. 114. Es importante constatar que la autora se refiere exclusivamente a los ingenios del entorno habanero.

71 Las cifras las tomo del apéndice estadístico incluido en Moreno Fraginals: El Ingenio..., t. III, págs. 43-48. La discrepancia entre los totales producidos, exportados y sus valores arancelarios y a precio real de mercado, se discute con tacto en Turu, Danielle: "Consideraciones sobre el valor real del azúcar cubano vendido en el siglo XIX: contrabando y evoluciones de aduana", Anuario de Estudios Americanos, t. XXXIV, 1979, págs. 607-632. Algunas consideraciones sobre estos aspectos, aunque para un periodo posterior, en los artículos de Tortella Casares, Gabriel: "El desarrollo de la industria azucarera cubana y la guerra de Cuba", Moneda y Crédito, 91, 1964, pp 131-163; y "La industria azucarera cubana, 1868-1895”, Moneda y Crédito, 96, 1966, págs. 15-31. 
y frente a la administración colonial, un protagonismo que sólo se verá desafiado por la conjunción entre el Estado liberal y los comerciantesbanqueros españoles en la segunda mitad del siglo XIX. ${ }^{72}$ El bien conocido acuerdo de la Junta de Gobierno del Real Consulado de La Habana de 21 de diciembre de 1796, de la mano de Arango y Parreño, señala el momento en que aquella hegemonía se constituye en un completo proyecto de desarrollo para la Isla. ${ }^{73} \mathrm{~A}$ pesar de todos estos indicadores, debería reconsiderarse con mayor atención la aparente invisibilidad de las fuentes en relación al lugar del primer o segundo sector de la agricultura cubana, durante e inmediatamente después de la devolución de La Habana. La respuesta no plantea ninguna dificultad: mientras que el azúcar y sus derivados fueron los sujetos pacientes por excelencia de los ajustes arancelarios post-1762, el tabaco permaneció estancado hasta 1817 y, por lo tanto, sustraído a la discusión arancelaria en las juntas de hacienda que se ocupaban de ello. Este hecho produce paradojas tales como que, a partir de las primeras cifras de la aduana de La Habana, los años 1803-1804, los últimos de recepción más o menos fluida de los situados de Nueva España, 779.068 y 674.717 libras de tabaco respectivamente, se valoren en ellas en 65.908 y 65.363 pesos, lo que significó el 1,29 y el 1,13\% de las exportaciones cubanas (en estos dos mismos años, el azúcar significó el

72 Esta preeminencia de los plantadores a partir de un cierto tamaño de la plantación la señaló ya Richard Dunn para el caso de las West Indies en: "The Molasses Act and the Market Strategy", Journal of Economic History, 17, 1, 1957, págs. 62-83.

73 Archivo Nacional de Cuba, Intendencia de Hacienda, 1126. "El plan de Trabajo recomendó como urgente la construcción de buenos caminos y puentes en la jurisdicción de La Habana; la del canal de Güines; la de la limpia de este puerto; el viaje de algunos jóvenes a las colonias vecinas para que nos comunicasen lo que fuese más útil en ellas; una obra en que se tratase de la mejor cultura de nuestros frutos; algún establecimiento para enseñar en la Habana las ciencias naturales; una caxa de descuento para socorrer a los hacendados; que entretanto se aumentase hasta el diez por ciento el interés legal en esta Isla; que se derogase el privilegio que tienen los ingenios para no ser rematados por deudas; que el Consulado decidiera los pleitos que sobre frutos de extracción ocurriesen entre los hacendados y comerciantes; que como una contribución de agricultura y comercio se administrase por la Junta la que se hace para el vestuario; que se libertase de derechos al azúcar que los vasallos del Rey estrageren de esta isla para puertos extranjeros; que se estudiase los medios de aumentar la introducción y disminuir el precio de los negros; que se estableciesen reglas más seguras y más justas sobre los esclavos prófugos; que se examinase y enmendase el sistema que hoy gobierna la demolición de las haciendas y corta de maderas (...) que se reformase la doble alcabala que hoy se cobra a los labradores en el repartimiento de tierras a censo redimible...". Solicitaban la reforma del reglamento de cimarrones, así como información sobre la capacidad de Cádiz para actuar como plaza de financiación, así como informaciones sobre el precio de los esclavos en el Brasil portugués y de la tecnología azucarera en Gran Bretaña. 
$84,11 \%) \cdot{ }^{74}$ Se trata a todas luces de cifras no homogéneas como resultado de la diferencia de condición comercial de los dos productos. Sin duda no es fácil calcular el precio unitario del tabaco enviado a España u otras partes del espacio imperial, tratándose de un producto estancado y que incluía por definición muchas variedades y calidades. Como elemento orientador, recuérdese que Alexander von Humboldt cifró en cinco millones de pesos el valor de las 128.000 arrobas que se mandaban a la Península en los años abundantes. Sobre la base de un nivel de precios similar, el valor de las exportaciones computadas en las balanzas analizadas por Nadia Fernández de Pinedo, para los años 1803-1804, debería superar con creces el millón de pesos fuertes. ${ }^{75}$ No sería razonable negar el impacto de la revolución azucarera, pero, como hemos visto, en este punto hay un problema contable muy arduo, aunque al mismo tiempo tan obvio como que la Real Factoría recibía, o esperaba recibir, unos cientos de miles de pesos anuales para compras de hoja, pagadas a precio de una tasación obviamente por debajo del precio en el mercado internacional, la única justificación de un monopolio fiscal. ${ }^{76} \mathrm{El}$ ascenso imparable del azúcar no fue óbice para que la Real Factoría se convirtiese, a partir de los años 1805-1806, en materia de discusión tanto en las covachuelas administrativas como en el espacio público habanero, a pesar de que los debates en torno al comercio exterior (con los norteamericanos para la importación de harinas y derechos sobre el azúcar) ocuparon un lugar central en los debates entre cubanos y españoles, tanto en La Habana como en Madrid, sobre la política económica en el ocaso del dominio español en la América continental.

74 Tomo estas cifras de la monografía de Fernández de Pinedo, Nadia: Las Balanzas del Comercio Exterior de La Habana, 1803-1807, Servicio Editorial de la Universidad del País Vasco, Bilbao, 2000, págs. 40-41. La autora reconoce, con toda honestidad, que "no nos ha sido posible averiguar el valor en pesos del tabaco en rama y en polvo, para algunos años..." y que, dado el régimen de monopolio, sucedía que "obligó a los vegueros a venderle determinadas cantidades de tabaco a precio fijo al año, no es posible averiguar exactamente cuál era el volumen real de ese producto.” (pág. 41).

75 Las cifras proporcionadas por la citada historiadora, para los años 1803 y 1804, son 779.068,5 y 674.717 arrobas (Ibídem, pág. 41).

76 El propio Alexander von Humboldt, tan preciso por lo general en sus informaciones, deslizó informaciones tendenciosas acerca del estanco tabaquero en su libro sobre Cuba. Su origen no es difícil de establecer dada su proximidad al propio Arango, de quien le distanciaba sin embargo su abolicionismo sincero. Al referirse a la Real Factoría, afirmaba lo siguiente: "La manutención de 120 esclavos y los gastos de fabricación no subían anualmente más que a 12.000 duros; pero los sueldos de los empleados de la Factoría ascendían a 514.000 duros." Esta es una evidente exageración. La cifra debe referirse al situado recibido para el pago de hoja a los vegueros. Ensayo político sobre la Isla de Cuba, Ediciones Doce Calles, Madrid, 1998, pág. 249. 
Si pensamos el desarrollo cubano en términos menos finalistas, es claro que el Estado mantuvo una doble estrategia entre la etapa decisiva que media entre la Guerra de los Siete Años y la quiebra definitiva del Imperio. Por un lado, profundizó hasta las últimas consecuencias el modelo de pacto colonial con los intereses de los hacendados del azúcar, que estaban ascendiendo como fuerza decisiva en el interior de la sociedad cubana y que, como acabamos de ver, contaban con un think tank de considerable potencia. Del otro, mantuvo un fuerte brazo hacendístico en la economía de la isla: el monopolio tabaquero. Esta cuestión tiene más implicaciones que las que se derivan de una lectura demasiado elemental de la política económica del Imperio tardío. La primera, que la organización del monopolio tabaquero fue anterior a la de la expansión de los estancos en el resto del imperio. ${ }^{77}$ Establecido a principios del siglo XVIII, el estanco del tabaco en Cuba fue relanzado como una importante operación de Hacienda justo antes de la invasión británica, seguramente a consecuencia del impulso que significó la apertura en Sevilla, en 1757, de la gran fábrica de tabacos, el segundo edificio monumental del país después de El Escorial. Cuando los grandes cambios provocados por la Guerra de los Siete Años, la Real Factoría de La Habana sobrevive al envite de las circunstancias, para convertirse, en los años noventa, en el blanco de las invectivas de los sacarócratas y de Arango (que había sido nada menos que su asesor electo y substituto del superintendente de la Factoría), justamente cuando el programa inversor de la Monarquía estaba perdiendo ritmo. ${ }^{78}$ La segunda de ellas es que el estanco del tabaco cubano no puede ser confundido, en absoluto, con el resto de los monopolios del mismo producto que se expanden por todo el espacio imperial, como una parte muy substantiva de las reformas borbónicas de los años que siguen a la visita de José de Gálvez a Nueva España. ${ }^{79}$ Como es bien conocido de los historiadores, el consumo del tabaco nunca fue estancado en Cuba. Lo que sí lo estaba era el cultivo de la planta, de cuya hoja la Real Factoría se convirtió en único comprador. La Hacienda real compraba hoja que después sería convertida en producto estancado, que se podía comercializar por el monopolio que se había

77 Céspedes del Castillo, G.: El tabaco en Nueva España, Real Academia de la Historia, Madrid, 1992.

78 Ponte Domínguez: Arango Parreño..., págs. 130-131.

79 Para Nueva España, la monografia de Deans-Smith, Susan: Bureaucrats, Planters and Workers. The Making of Tobacco Monopoly in Bourbon Mexico, University of Texas Press, Austin, 1992. 
implantado en España durante el gobierno del conde duque de Olivares, en el año 1636. Aunque la Hacienda española ya tenía factores en la isla desde fines del sigo XVII para la compra de tabaco, la organización del ramo como monopolio no se hizo efectiva hasta 1717 , un cambio de política que provocó dos importantes levantamientos del pequeño campesinado productor, los vegueros.

Más tarde, cuando las reformas borbónicas situaron los estancos del tabaco como la renta de mayor rendimiento y autonomía a la hora de mandar efectivo a la Península, la Real Factoría habanera sería obligada a enviar importantes partidas de hoja cubana a los monopolios fiscales de nuevo cuño del continente. Se trataba, por lo tanto, de un monopolio exportador, razón que explica sin mayores problemas por qué la Real Factoría era una receptora tan importante de situados procedentes de Nueva España y de otras partes del Imperio e incluso de Canarias. Situados que, en este caso, no eran transferencias netas, producto de decisiones políticas en función de las necesidades estratégicas del Imperio, sino pagos por la hoja recibida. Esto explica también que, cuando las haciendas continentales entren en una época de inestabilidad financiera indiscutible, la Real Factoría pase por apuros muy serios para reintegrar a la pequeña unidad campesina productora el valor de la hoja avanzada a otras administraciones. El problema era de proporciones notables: desde 1799 a 1806 la agencia compradora en La Habana acumuló impagados de otras partes del espacio imperial por un valor de 3.385.994 pesos (sobre un total de 11.324.224 que se adeudaban a la hacienda cubana). ${ }^{80}$ La caída de las aportaciones novohispanas a la Real Factoría, en pago de hoja o como situado tabaquero para comprar tabacos para la Península, es transparente: 1.069.010 en $1798 ; 909.010$ al año siguiente; 753.436 en $1800 ; 513.634$ en 1801; 585.923 un año después, 338.672 en 1803 y 207.672 en $1804 .{ }^{81}$ En aquellas condiciones, el crédito de los particulares (los inevitables condes de Casa Barreto y de Mopox, junto con algunos financieros de la plaza) y la ayuda de la Hacienda de la isla llenan en la medida de lo posible el vacío que deja, imparable, la bancarrota de todo el sistema imperial. La Real

80 Archivo Nacional de Cuba, Intendencia, 1132, $\mathrm{n}^{\circ} 5$. Estado de cuentas presentado a la Junta Extraordinaria de Hacienda por Gómez Robaud, el gran adversario intelectual de Arango.

81 AGI, Audiencia de Santo Domingo, 1859-1860. No disponemos de cifras para los años 1805-1808. En 1809 recibió 610.000 pesos más, probablemente de atrasos. Según Ramón de la Sagra, las remesas de situados y para la Real Factoría evolucionaron del modo siguiente: entre 1788 y 1799 , 49.845.661de pesos; 1799-1802, 6.142.352; en 1803, 1.686.920; y 184.000 para seis meses del 1804 . Historia Económico-política..., pág. 302. 
Factoría se convierte, así, en un rehén de la debacle financiera general, lo que impide una evaluación fácil de sus resultados en la fase crepuscular, aquellas carencias "antieconómicas" que Arango y sus colaboradores ponen de relieve a partir de 1804-1806. ${ }^{82}$ La acumulación de impagos era, sin duda, el punto débil del estanco, sobre todo si lo analizamos no como una estricta cuestión financiera - cuya importancia no escapa a nadiesino además como un problema con ramificaciones mucho más amplias, como veremos luego. Una de ellas, la puntualidad de los pagos a los vegueros, ya había sido la causa de las sublevaciones de la segunda y tercera década del siglo XVIII, y volvió a ser una amenaza real durante la crisis de fin de siglo, cuando los desajustes en el sistema de situados vuelvan a reproducir la situación a una escala ampliada. Este es un punto crucial, si entendemos bien los complejos sistemas de formación de una sociedad campesina en torno a un cultivo intensivo y muy técnicamente exigente como el del tabaco. La Real Factoría estaba genuinamente implicada en el control de la calidad del producto y, por supuesto, supervisaba con rigor las siembras y colecciones (el punto más crítico del informe de Arango era el de las quemas de tabaco "injuriado") ${ }^{83}$ Ahora bien, estos factores de control sobre el mundo rural eran la otra cara de la actividad del estanco: del pequeño crédito y, lo que es todavía más importante, del suministro a escala muy modesta de la mano de obra esclava, que complementaba el de la familia campesina.$^{84}$ Estamos, por lo tanto, frente a un mundo totalmente distinto al del azúcar: uno que vinculaba a través del sistema de situados a una economía a escala imperial con el protagonismo de la administración de hacienda y con la formación de una economía campesina ligada al mercado a través del aparato imperial. Éstas eran algunas de sus características fundamentales. Esta contraposición entre los dos sectores es un elemento clave para entender la ofensiva frontal de los hacendados del azúcar contra la Real Factoría, pero antes de acercarnos a este punto final conviene introducir una muy pertinente comparación con Filipinas.

82 Sobre el estanco tabaquero cubano no existe ninguna monografía reciente. Debe reseñarse el trabajo de José Rivero Muñiz, Tabaco: su historia en Cuba, La Habana, Instituto de Historia, 1964, 2 vols.

83 "Informe del D. Francisco Arango y Parreño al Sr. D. Rafael Gómez Robaud, Superintendente Director General de Tabaco en la Isla de Cuba, sobre los males y remedios, que en ella tiene este ramo, escrito en 1805", Obras de Francisco Arango y Parreño, t. I, págs. 441-445.

84 Nada comparable al mundo del azúcar. Una persona tan bien informada como Ramón de la Sagra estableció una proporción entre trabajadores libres y esclavos en las vegas tabaqueras de 3:1. Historia económico-política..., t. II, pág. 120. 
En la lejana posesión asiática el monopolio tabaquero y el de los alcoholes nativos de nipa y coco se convirtió en la gran solución al problema de la bancarrota virreinal e imperial. Sin embargo, cuando el enérgico capitán general José Basco y Vargas optó por constituir un potente ramo de estancadas en el año 1782 (el de alcoholes se había formado en la década de 1730, pero fue reformado por completo), fue una decisión de orden político en el contexto del debate interno que se había producido, a partir de 1764, sobre el devenir de la colonia y sobre las recetas de Hacienda necesarias para sostener el esfuerzo militar que la Monarquía se proponía. ${ }^{85} \mathrm{Se}$ demostraría una resolución de importancia crucial, cuyo éxito superó con creces las expectativas de los funcionarios más optimistas. Su planta fue estructurada conforme a las ordenanzas de la renta en Nueva España y, como ella, los activos generados en Filipinas deberían pasar directamente a las arcas de la metrópolis. ${ }^{86} \mathrm{El}$ establecimiento del monopolio tabaquero se organizó en los momentos iniciales con el propósito de atender al consumo de cigarros en la capital-puerto y las provincias arroceras limítrofes. No era una decisión libre de costes: exigía el desplazamiento de un pequeño, pero activo, grupo de chinos y de mestizos de sangley (filipinos con sangre china) del negocio y controlar las siembras hasta entonces libres. ${ }^{87}$ No era algo fácil, sin duda, pero esta fue la gran apuesta del aparato colonial en el archipiélago. Basco y Vargas consideró con razón que fiar una mayor capacidad recaudatoria a la extensión de las redes del tributo indígena, incluso recuperando una parte de lo que se embolsaban las órdenes regulares, o a los beneficios futuros de las operaciones de la fraudulenta Compañía de Filipinas era especular con plazos demasiado largos. El crecimiento de la actividad de los estancos, en particular del tabaco, y las remesas que se podían remitir a la Península le dieron la razón. A partir de 1782 el estanco tabaquero se perfila como un instrumento nada desdeñable de recaudación, seguido a distancia por el de los alcoholes nativos. En los

85 Sobre estas disyuntivas y trasfondo de la organización del monopolio, Fradera, Josep M.: Filipinas, la colonia más peculiar. La hacienda pública en la definición de la política colonial, CSIC, Madrid, 1995, págs. 71-131.

86 Sobre el estanco del tabaco en Filipinas existe una importante monografía de Jesús, Edilberto de: The Tobacco Monopoly in the Philippines. Bureaucratic Enterprise and Social Change, 1766-1880, Ateneo de Manila, Quezon City, 1980.

87 Así como a una microburguesía nacida en el mundo del azúcar, en la provincia de Pampanga principalmente, que compitió con el estanco de los alcoholes para comercializar alcoholes de caña de mayor graduación que los de nipa y coco, que eran los estancados. Una excelente presentación a largo plazo en Larkin, John: Sugar and the Origins of Modern Philippine Society, California University Press, Berkeley, 1995. 
ocho años entre 1783 y 1795, para los que tenemos cifras, las remesas del monopolio a la Hacienda metropolitana fueron de 1.970 .000 pesos fuertes, lo que representaba en torno al $95,16 \%$ del producto neto de la renta. Las prioridades imperiales eran en este sector tan manifiestas como sabidas, aunque resultaban particularmente sangrantes ya que en nada se habían incrementado, en contra de lo prometido, los situados novohispanos hacia la posesión del Mar de China cuando la fase crítica de constitución de la renta. El ciclo de conexión imperial de Filipinas estaba a punto de cerrarse. En el 1800, cuatro años antes de que las órdenes procedentes de Nueva España comunicasen al capitán general en Manila el fin del situado, los ingresos del estanco tabaquero pasaron a computarse entre las rentas filipinas. Se computaron todavía entre los fondos disponibles de las cajas reales, en el epígrafe de "real hacienda en común", por lo tanto todavía no entre los generados en y para Filipinas. ${ }^{88}$ Tan sólo a partir de 1810, los ingresos de los dos estancos se convirtieron de pleno derecho en ingresos de la Hacienda filipina.$^{89}$ No sólo eso, sino que superando en ocasiones el medio millón de pesos anuales pasarán a situarse en el primer lugar entre los ingresos de la Hacienda filipina, la única alternativa válida a la quiebra de los situados transpacíficos. ${ }^{90}$

Sin embargo, los monopolios fiscales, que fueron una parte tan relevante del reformismo borbónico, no resistieron en todas partes el cambio de las circunstancias políticas. El desestanco del tabaco en Cuba, por un real decreto del 23 de junio de 1817, fue una de las únicas medidas de los hacendistas del absolutismo restaurado de Fernando VII en línea con las intenciones reformistas del primer intento liberal en España. ${ }^{91}$ Antes, durante las guerras napoleónicas, las Cortes gaditanas habían abolido el estanco del tabaco en todos los dominios de la Monarquía. Como tanta legislación de las Cortes, se trató de una abolición sobre el papel, aunque su gestación delataba las presiones de los cubanos contrarios al sistema de

88 Sobre aquel apartado repercutió la contribución de Filipinas a la guerra contra los ejércitos napoleónicos en España.

89 Fradera: Filipinas, la colonia más peculiar..., pág. 127.

90 Dejo para otro lugar la discusión sobre los elevados costes de recaudación de los monopolios fiscales. Aun considerando esta circunstancia, los ingresos de los dos estancos constituían la indiscutible base de sustentación de la hacienda pública filipina. Esto sería así hasta su desestanco: en 1863 el monopolio sobre los alcoholes nativos y en 1882 el del tabaco. Es decir, cien años después de su constitución por Basco y Vargas.

91 Puede consultarse, junto con otros materiales sobre el ramo, en la Biblioteca de Legislación Ultramarina en forma de diccionario alfabético, Imprenta de J. Martín Alegría, Madrid, 1846, págs. 5-9. 
Real Factoría, como puede apreciarse por la mención directa en el artículo noveno del decreto, que sólo por extensión generalizaba la medida al resto de los dominios ultramarinos..$^{92}$ El gobierno en guerra contra el invasor no disponía de recursos para imponer el justo y congruente propósito de acabar con la pesada carga de impuestos indirectos. En el élan de reforma liberal resuenan los ecos de las críticas inmisericordes que Arango y los suyos habían vertido contra la Real Factoría, así como las desventuras contables del monopolio virreinal. ${ }^{93}$ Por esta razón, los americanos fueron los portavoces más entusiastas de tan sabias medidas. Tras el diluvio reaccionario de 1814, aquella política antimonopolios parecía sentenciada para siempre. Sin embargo, reapareció magnífica, vestida con los más brillantes ropajes del liberalismo de Adam Smith (que delatan con toda probabilidad la pluma del propio Arango), con el fin de acabar de una vez para siempre con la Real Factoría habanera: “...las que ofrecía el tabaco de la isla de Cuba por su sobresaliente calidad y exquisito gusto, no habían tenido efecto por haberse desviado del camino que dictaban la razón y los buenos principios, cual era el de la libertad y protección, sin las cuales ningún cultivo puede prosperar." ${ }^{94}$ El pie fiscal del Estado desapareció sin dejar rastro y para siempre, aunque el estanco en España mantuviese sus compras de tabaco cubano sin interferir en la emergencia de un sector libre tabaquero (los llamados "marquistas"), que toma forma a principios de la década de 1830.

La disposición desestancadora — que permitía, esta vez, que "subsista por ahora" en el Perú, Nueva España y Filipinas- llegó a Manila el 11 de noviembre de 1818, acompañada de una real orden firmada por Martín de Garay, en la que se ordenaba a las autoridades proceder de acuerdo con ella. No es difícil imaginar su estupor ante una disposición que amenazaba, de haberse cumplido, con hundir la balsa de la Medusa en la que se había convertido la posesión asiática una vez que quebró su vinculación secular con Nueva España. El ministro ponía en evidencia su absoluto desconocimiento de lo que la renta significaba en Filipinas al preguntarse "sobre las causas que pueden influir en el corto consumo de tabacos, y si convendrá su desestanco en este territorio de su mando, proponiendo en este caso los medios de asegurar los productos equivalentes para que a su vista acordar lo que convenga." ${ }^{95}$ La real orden ni se obedeció ni se cumplió, como era de esperar. Al

92 Archivo Nacional de Cuba, Gobierno Superior Civil, 40.589, $\mathrm{n}^{\circ} 1.100$.

93 Esta cuestión se desarrolla extensamente en el capítulo tercero de esta obra.

94 Biblioteca de Legislación Ultramarina..., t. VI, pág. 6.

95 Philippine National Archives, Cedulario, 1817-1820, Manila, 11 de noviembre de 1818. 
contrario, el director de la renta expidió un extenso informe en el que se daba cuenta de los progresos de la renta y de su expansión por toda la isla de Luzón. ${ }^{96}$ Una vez restablecido el marco constitucional en 1820, el capitán general Mariano Fernández de Folgueras remitió una nota al intendente de Hacienda, Luis Urrejola, en la que le señalaba que "está prevenido que no se haga novedad en el sistema de rentas de Ultramar." ${ }^{97}$ Un estado preparado por los funcionarios de Hacienda de Manila en 1823, que resumía los resultados del quinquenio anterior de 1816 a 1820, dejaba bien claras las razones de tal inmovilismo. Los tributos personales aportaban el 25,87 de los ingresos; los derechos de aduana el 5,9\% y las rentas estancadas el 57,25\% (42,15 la del tabaco y 15,10 la de los alcoholes). ${ }^{98}$ Cuando en la década siguiente la colección de Cagayan (que hacia 1850 incluía unas treinta mil familias cultivadoras) sea definitivamente organizada, el monopolio adquirirá su mayoría de edad, que le permitirá sortear los avatares de la historia colonial filipina hasta el año 1882.

El caso de Puerto Rico tiene su perfil propio. A medio plazo, fueron los derechos arancelarios sobre el comercio exterior los que sostuvieron la Hacienda pública. Sin la existencia de un sector económico hegemónico como el del azúcar en Cuba, fue la proximidad con las Antillas de otros países, en particular con la danesa Saint Thomas que actuaba como puerto franco, el acicate principal del empuje de su capacidad exportadora. ${ }^{99}$ Desde fines del siglo XVIII y hasta la segunda mitad del siglo XIX, el café y el azúcar se desarrollan en paralelo, con una división del trabajo geográfica y social ciertamente notable, seguidos a cierta distancia por el tabaco y el algodón. ${ }^{100} \mathrm{~A}$ falta de un interlocutor claro con quien establecer las condiciones de un nuevo pacto colonial, la administración española en la isla se acomodará a las circunstancias particulares de la estructura social puer-

96 Fradera: Filipinas, la colonia más peculiar..., pág. 131, nota 141.

97 Philippine National Archives, Cedulario, 1820-1822, s.p.

98 AGI, Ultramar 646, 3 diciembre de 1823.

99 Una visión general que muestra el equilibrio entre los dos sectores principales, cafetalero y azucarero, hasta la poderosa arrancada del segundo en 1820, en Dietz, James L.: Economic History of Puerto Rico. Institutional Change and Capitalist Development, Princeton University Press, Princeton, 1986, pág. 17.

100 Sobre el azúcar puertorriqueño debe consultarse el trabajo de Scarano, Francisco A.: Sugar and Slavery in Puerto Rico. The Plantation Economy of Ponce, 1800-1850, The Wisconsin University Press, Madison, 1984; sobre el café, Bergad, Laird: Coffee and the Growth of an Agrarian Capitalism in Nineteenth-Century Puerto Rico, Princeton University Press, Princeton, 1983; para un periodo un poco más tardío, los de Fernando Picó, en especial: Amargo café (los pequeños y medianos cafeicultores de Utuado en la segunda mitad del siglo XIX), Edicions Huracán, Río Piedras, 1985. 
torriqueña. Con los comerciantes de San Juan pactará unos determinados niveles de presión sobre un comercio de exportación. ${ }^{101}$ Con anterioridad, la administración española ya había tratado de hacer llegar el brazo fiscal del Estado hasta la propiedad territorial con figuras tributarias nuevas. El primer impulso debe situarse hacia mediados del siglo XVIII, en un momento en el que se producen simultáneamente dos desarrollos distintos. El primero fue la formación de la Compañía de Barcelona en 1755, con autorización para comerciar con Santo Domingo y Puerto Rico. ${ }^{102}$ El segundo fue el ambicioso plan de fomento del café en el interior de la isla dirigido por el capitán general Felipe Remírez de Estenós, que había llegado a la isla en $1753 .{ }^{103}$ Para ello se propone repartir tierras realengas, muchas de las cuales se habían convertido en hatos ganaderos en un proceso de apropiación por parte de los vecinos ricos de los municipios del lugar. Remírez Estenós optó desde el principio por incentivar la ocupación agrícola de la mano de medianos agricultores con pequeñas dotaciones de esclavos. No es fácil saber el impacto de estas medidas, lo que sí es seguro es que provocaron una gran oposición en lugares como San Germán. No obstante, el conflicto clásico entre ganaderos y agricultores se produce en distintos puntos de la isla. ${ }^{104}$ En 1757, además, el brigadier fue ascendido a capitán general de Venezuela. Un poco más adelante, en 1775, en tiempos del capitán general Miguel de Muesas, se articulará un "impuesto de tierras" como contrapartida del reconocimiento que se había producido del derecho de uso sobre terrenos cuyo titular nominal era la Monarquía ${ }^{105}$ Es interesante notar que se debe a aquel personaje, clave en la definitiva reorganización de los cuerpos militares de la isla, la propuesta de organizar en ella un

101 Para todas estas cuestiones es indispensable la consulta de los trabajos de Birgit Sonesson, en particular su Puerto Rico's Commerce, 1765-1865. From Regional to Worlwide Market Relations, UCLA Latin American Center Publications, Los Angeles, 2000; Campos Esteve, Carmen: La política del comercio: los comerciantes de San Juan, 1837-1844, Tesis de maestría inédita, Universidad de Puerto Rico, Río Piedras, Puerto Rico, 1987.

102 Sobre la Compañía, consúltese el exhaustivo trabajo de Oliva, José María: Cataluña y el comercio privilegiado con América, Publicaciones de la Universitat de Barcelona, Barcelona, 1987.

103 Tomo estas informaciones de Morales Carrión, Arturo: Historia del Pueblo de Puerto Rico: desde sus orígenes hasta el siglo XVIII, Editorial Cordillera, San Juan de Puerto Rico, 1985, págs. 220-222.

104 Picó, Fernando: Historia General de Puerto Rico, Ediciones Huracán, Río Piedras, 1988, págs. 108-109.

105 Es muy interesante notar que la base estadística y el proyecto mismo sobre el que se levantó el impuesto territorial había sido preparado por el coronel Tomás O’Daly, él mismo un hacendado del azúcar y tabaco, y consejero áulico para las reformas militares de O'Reilly y Muesas. Tomo esta información de Ortiz, Altagracia: Eighteenth-Century Reforms in the Caribbean. Miguel de Muesas, Governor of Puerto Rico 1769-1776, Associated University Presses, Rutherford, 1983, págs. 173-175. 
estanco tabaquero a imagen de la Real Factoría de La Habana. ${ }^{106}$ Sin embargo, aquel modesto estanco, que envió su primer cargamento en 1787 y que se mantuvo hasta 1792, no estaba pensado para canalizar tabaco en rama hacia la Península sino para venderlo directamente en los mercados del norte de Europa, una liberalidad corta en el tiempo que sólo se puede explicar por la exigencia de encontrar desesperadamente recursos en un contexto genuinamente periférico del Imperio y por la voluntad de canalizar legalmente lo que antes se hacía de contrabando. ${ }^{107}$ La contribución territorial avant la lettre impuesta durante el mando de Muesas fue de escaso rendimiento hasta la segunda década del siglo XIX, pero constituyó un precedente importante. En 1815, Alejandro Ramírez —el futuro intendente cubano que tuvo la responsabilidad de desestancar la Real Factoría de La Habana - establecerá una contribución territorial, el llamado "subsidio", sobre la propiedad territorial, que era algo impensable en Cuba, al tiempo que reorganizaba las aduanas y trataba de controlar la crisis monetaria desatada por las emisiones de papel moneda con que el gobernador Meléndez había tratado de paliar, en 1810, el agujero financiero que comportó el fin de las remesas novohispanas. ${ }^{108}$ Finalmente, facilitará el establecimiento de inmigración no-española procedente de las otras Antillas o de la Europa católica, en la conocida como la Cédula de gracias de 10 de agosto del mismo año. Esta disposición fue vista en el pasado como el principio del importante desarrollo de la agricultura de exportación puertorriqueña del siglo XIX, una simplificación abusiva en la medida en que no la sitúa adecuadamente en el contexto de los cambios que estaban ocurriendo tanto en el espacio interior insular como en el contexto internacional. ${ }^{109}$

\section{Los límites del poder colonial}

El hilo conductor que unió las críticas de los cubanos a la Real Factoría habanera, hasta la real orden que sentenciaba su definitivo desestanco en 1817, es revelador de algo que escapa a una evaluación estricta de las fuerzas económicas en presencia en aquellas pugnas, para establecer el

106 Ibídem, pág. 182.

107 Sonesson: Puerto Rico's Commerce..., págs. 31-32.

108 Gónzalez Vales, Luis: Alejandro Ramírez y su tiempo. Ensayos de historia económica e institucional, Editorial Universitaria, Río Piedras, 1978, págs. 44-46.

109 Picó: Historia General..., págs. 132-133. 
lugar de cada cual dentro del gran Imperio en su fase crepuscular. Algo que merece, sin duda, consideración. Me refiero a los pactos políticos que se imponen - o quiebran - en cada uno de los contextos insulares y, por supuesto, que se hunden con estrépito en los centros de gravedad del imperio en el continente. Cuba y Filipinas muestran, a pesar de todas la diferencias, el alcance de las políticas posibles en una misma coyuntura, sin romper con el marco imperial. El caso de Puerto Rico puede situarse con comodidad en la descripción que estamos tratando de dibujar, pero tiene, como hemos visto, sus particularidades específicas que no pueden disolverse en observaciones de orden general.

En el debate del cambio de siglo, Arango y Parreño apuntó directamente hacia un modelo que retomase la experiencia azucarera y plantadora del Caribe del siglo XVIII y que mirase, también, hacia el modelo norteamericano de Virginia y los estados limítrofes hacia los que se estaba desplazando la frontera del cultivo del tabaco en la vecina república. La gravedad de las dificultades que la intermitencia de los situados comportaron al estanco no era una cuestión que mereciese demasiada atención del habanero. En 1805 hablaba de reforma de la Real Factoría, pero de una reforma que contenía toda la sustancia del desestanco de 1817: "Esta palabra reforma, tomada rigurosamente, explica toda mi idea. Quiero decir con ella que la Factoría se reduzca a lo que claramente indican las instrucciones que trajo para establecerse; que se acuerde que no vino a ejercer autoridad, ni a conseguir por ese medio lo que sólo puede lograrse con buenas combinaciones; que no se ocupe que de comprar con ventaja y remitir con cuidado." 110 (El subrayado es mío) Un monopolio estatal sin "autoridad" hubiese sido como un tigre de papel. Formulado de otra manera, Arango podía lamentar la disminución de la llegada de situados, pero no estaba dispuesto a dejar de aprovechar uno de los efectos colaterales de la crisis fiscal novohispana: conducir a la Real Factoría a una práctica quiebra por acumulación de incobrables. La posición de Arango era una opa hostil sobre la administración colonial española, sobre este punto no cabe engañarse. Ni conviene tampoco negar la multiplicidad de razones que motivaban la animadversión al estanco tabaquero. ${ }^{111}$ Tan sólo la maduración de la propia crisis imperial — la dependencia finan-

110 "Informe de D. Francisco de Arango al Sr. Rafael Gómez Robaud...”, t. I, pág. 469.

111 Con muy buen criterio, Manuel Moreno Fraginals apuntó entre ellas la apetencia de tierras de los azucareros. En sus propias palabras: "El desplazamiento tabaquero fue sólo un episodio, aunque de gran importancia social, en la transformación cubana del régimen de tierras." El ingenio..., t. I, pág. 62 . 
ciera del monopolio tabaquero respecto a la misma Hacienda cubana - conduciría el proceso hasta sus últimas consecuencias. A partir de 1817 el pulso de los cubanos con la administración española es una historia digna de ser contada, por atípica, en las relaciones coloniales que han sido desde que el mundo es mundo. El intendente de Hacienda Alejandro Ramírez impone uno tras uno los puntos del programa esbozado por los hacendados del azúcar, incluyendo el desestanco del tabaco. Es un momento de extrema debilidad española, de una potencia en harapos que vuelca la poca capacidad logística que le resta en el insensato intento restauracionista de Morillo en Venezuela. La administración de la Isla estaba casi en manos cubanas, o de peninsulares muy identificados con el programa de plantación a gran escala de los criollos. En aquellas condiciones, el pacto colonial era claro. De un lado, liberalización completa de la economía cubana, libertad de importación de brazos y del comercio exterior. Del otro, formación de un impresionante dispositivo militar en la Isla, el baluarte frente a la América bolivariana, y participación del Estado en los beneficios del comercio exterior cubano, más el importante añadido, a partir de 1825, de una aportación anual de las arcas cubanas a la maltrecha hacienda particular. En pocas palabras, entre 1804 y 1825 se invierte la dirección de los situados: Cuba pasa de receptora a suministradora. Esta no fue una división del trabajo suavemente pactada, como dos acontecimientos lo jalonan de modo preciso. El primero señala el momento de mayor autonomía de los cubanos en aquel marco: el rechazo de las autoridades de la Isla a la aplicación del arancel de 1820, que los liberales de nuevo en el poder imaginan hacer extensivo a todo el espacio de la Monarquía. El proteccionismo a los cereales españoles no podía ser aceptado por los cubanos y el arancel tuvo que ser retirado, con oprobio, sin llegar a aplicarse. El segundo, refleja la reversión de la tendencia. En 1825, defenestrado Arango y Parreño de la Intendencia, una Junta de Auxilios propone remedios para aliviar a la metrópolis. En la pugna en torno a los gravámenes arancelarios empezará a pesar con mayor fuerza el interés metropolitano, una tendencia que se prolonga inexorable hasta 1837, cuando Mendizábal como ministro de Hacienda recuperó para los gobiernos españoles la facultad de elaborar e imponer los derechos arancelarios que iban a regir en la más importante de las tres colonias de la Monarquía. ${ }^{112}$

112 El contexto político de esta medida en Fradera, J. M.: "Why were Spain's special overseas laws never enacted?, en Kagan, Richard L. y Parker, Geoffrey (eds.): Spain, Europe and the Atlantic World. Essays in honour of John H. Elliott, Cambridge University Press, Cambridge, 1995, págs. 334-349. 
Filipinas sigue la pauta contraria. Allí, el poder colonial se convirtió en el instrumento más relevante de formación de renta. La importancia del desarrollo del sistema de dos grandes monopolios fiscales no puede minimizarse en absoluto, ni puede reducirse a un mero expediente fiscal. El poder colonial era al mismo tiempo el primer agente económico del archipiélago, un hecho que no impidió, sino todo lo contrario, la emergencia de todo un conjunto de pequeños pero dinámicos sectores económicos (azúcar en Pampanga y, más tarde, en Negros; abacá en los dos Camarines y Albay; café en Batangas) a lo largo de la primera mitad del siglo XIX.113 El estanco tabaquero, con su impacto en términos de división del trabajo entre provincias, su importante papel en el comercio exterior y en su desplazamiento de la carga fiscal hacia el consumo popular, liberando las rentas del capital y, last but not least, haciendo gravitar sobre ellas el peso de la explotación fiscal de la colonia, estructuró una peculiar vía al capitalismo en la cada vez más remota posesión española hasta la apertura del canal de Suez. ${ }^{114}$ Pero la imposición de una fórmula de hacienda no puede ser entendida tan sólo en estos términos. Los altos costes de recaudación de los ramos que más aportaban a la Hacienda filipina, los monopolios fiscales y el tributo de naturales (que se siguió cobrando bajo el nombre de capitación personal una vez que el liberalismo se impuso en España), eran el resultado, en parte, de la internalización de los costes reales de colonización sobre el territorio, aquellos que antes, con el sistema de situados y del comercio transpacífico, no habían figurado ni remotamente en el horizonte mental de los capitanes generales de Manila. ${ }^{115}$ A partir de los años treinta, aquel modelo tan auto-centrado, sostenido por un estanco tabaquero de circularidad perfecta, inició una etapa de mayor apertura al comercio internacional, la otra cara de sus obligaciones hacia la Hacienda española (que la obligaba a la aceptación de letras giradas contra la Hacienda colonial o a remesar tabaco en rama hacia el estanco metropolitano con coste casi cero para aquélla).

113 Para el azúcar, Larkin: Sugar and the Origins...; además, McCoy, Alfred W.: "A Queen Dies Slowly: The Rise and Decline of Iloilo City", en McCoy, Alfred W. y Jesús, Edilberto de (eds.): Philippine Social History: Global Trade and Local Transformations, Ateneo de Manila Press, Quezon City, 1982, págs. 155-190; para el abacá, Owen, Norman G.: Prosperity without Progress. Manila Hemp and Material Life in the Colonial Philippines, University of California Press, Berkeley, 1984.

114 Como puede observarse, esta posición disiente de la expuesta por Norman G. Owen en: "Fomento and the Free market: the 19 $9^{\text {th }}$-Century Philippine Economy", con su énfasis en la debilidad del gasto público del Estado como factor determinante. Elizalde, Ma. Dolores, Fradera, Josep M. y Alonso, Luis (eds.): Imperios y naciones en el Pacífico, CSIC, Madrid, 2001, págs. 133-149.

115 Fradera: Filipinas, la colonia más peculiar.., pág. 234. 
Los casos de Cuba y Filipinas muestran dos modelos de reproducción colonial, del paso del Imperio al sistema de tres colonias, dos fórmulas distintas de adaptación a la quiebra del sistema de situados. No existió un solo camino de salida de la crisis del gran imperio, del paso de la periferia imperial al centro del sistema de tres colonias del siglo XIX. Las modalidades de la transición dependieron, en definitiva, de las circunstancias locales. En Cuba, el poder colonial reforzado militarmente por las reformas borbónicas retrocedió, incluso en lo económico, frente a la ofensiva de un grupo social emergente que no se encontró con conflictos frontales con la metrópolis, hasta que el miedo al esclavo, la llegada de un contingente importante de emigrantes peninsulares y el abandono militar y político del continente, permitieron a la potencia colonial recuperar parte de la iniciativa perdida. Francisco de Arango lo expresó mejor que nadie en 1821, en un momento de gran tensión en La Habana y de extrema debilidad del Estado: “...en toda la extensión de mis noticias, no alcanzó ningún gobernador, cuya memoria no sea grata por más o menos motivos, y todos, sin exceptuar uno, han parecido como competidores en el más escrupuloso desinterés: que en provisión de empleos fuimos atendidos sin agravios notables; y que en franquicias mercantiles, aun debajo del poder absoluto, no experimentamos restricciones injustas, pues no se ejecutaban las que la intriga o el error despachaban contra el comercio libre, sin que jamás el gobierno se irritara por esta conducta, si como tampoco ahora se ha indignado el gobierno constitucional por las representaciones y suspensión del arancel (...) Así se ha visto la Habana, que, habida proporción a su población, es el pueblo con mayor número respectivo de propietarios, ha sido también la sociedad más tranquila en los treinta años últimos de más convulsiones políticas del universo." ${ }^{16}$ En ausencia de un grupo de intereses con quien pactar, por el contrario, la administración colonial filipina optó por desarrollar a fondo todo el potencial que las reformas borbónicas habían puesto encima de la mesa, económica y políticamente, que todo era uno. $\mathrm{O}$, como señaló de forma retrospectiva un modesto funcionario español del gobierno de Manila, elevando la anécdota a categoría: "En Filipinas no hay elementos ni disposición alguna para revoluciones políticas. Si en algún tiempo hubo ilusiones, desaparecieron con severos escarmientos. Pueden ocurrir motines o sediciones parciales, como las de 1823,1841 y 1843 que

116 "Independencia de la isla de Cuba", citado por Sevilla Soler, Ma Rosario: Las Antillas y la Independencia de la América Española, CSIC, Sevilla, 1986, pág. 144-146. 
inmediatamente es fácil sofocar si el ejército, como es de esperar, se conserva fiel." ${ }^{117}$ Dos procesos distintos, en definitiva, que están en la base de un nuevo ciclo colonial de cien años que no fue la mera continuación del pasado, como los paradigmas interpretativos que impuso y divulgó el imperialismo antiimperialista norteamericano a partir de 1898 dejaban entender. ${ }^{118}$ Sólo mirando hacia atrás, hacia los forcejeos políticos y económicos en la última fase del Imperio (que se resumen mal en el concepto de "reformas borbónicas") y su resolución en el plano local, las cosas se ordenan de forma razonable.

117 Archivo Histórico Nacional (Madrid), Ultramar, 2.584.

118 Sobre cómo la continuidad española en las Antillas fue vista y presentada, véase UcelayDaCal, Enric: "Self-Fulfilling Prophecies: Propaganda and political models between Cuba, Spain and the United States", Illes i Imperis, 1999, 2, págs. 191-219. 